\title{
Modeling drug- and chemical-induced hepatotoxicity with systems biology approaches
}

\author{
Sudin Bhattacharya ${ }^{1}{ }^{*}$, Lisl K.M. Shoda ${ }^{2}$, Qiang Zhang ${ }^{1}$, Courtney G. Woods ${ }^{1}$, Brett A. Howell ${ }^{2}$, \\ Scott Q. Siler ${ }^{2}$, Jeffrey L. Woodhead ${ }^{2}$, Yuching Yang ${ }^{2}$, Patrick McMullen ${ }^{1}$, Paul B. Watkins ${ }^{2}$ and \\ Melvin E. Andersen ${ }^{1}$
}

1 Institute for Chemical Safety Sciences, The Hamner Institutes for Health Sciences, Research Triangle Park, NC, USA

2 Institute for Drug Safety Sciences, The Hamner Institutes for Health Sciences, Research Triangle Park, NC, USA

\section{Edited by:}

Hans Westerhoff, University of

Manchester, UK

Reviewed by:

Steven G. Gray, St. James

Hospital/Trinity College Dublin, Ireland

Noriko Hiroi, Keio University, Japan

Daniel Kaschek,

Albert-Ludwigs-Universität Freiburg,

Germany

${ }^{*}$ Correspondence:

Sudin Bhattacharya, Institute for Chemical Safety Sciences, The

Hamner Institutes for Health

Sciences, Research Triangle Park, NC

27709, USA.

e-mail: sbhattacharya@thehamner.org
We provide an overview of computational systems biology approaches as applied to the study of chemical- and drug-induced toxicity. The concept of "toxicity pathways" is described in the context of the 2007 US National Academies of Science report, "Toxicity testing in the 21st Century: A Vision and A Strategy." Pathway mapping and modeling based on network biology concepts are a key component of the vision laid out in this report for a more biologically based analysis of dose-response behavior and the safety of chemicals and drugs. We focus on toxicity of the liver (hepatotoxicity) - a complex phenotypic response with contributions from a number of different cell types and biological processes. We describe three case studies of complementary multi-scale computational modeling approaches to understand perturbation of toxicity pathways in the human liver as a result of exposure to environmental contaminants and specific drugs. One approach involves development of a spatial, multicellular "virtual tissue" model of the liver lobule that combines molecular circuits in individual hepatocytes with cell-cell interactions and blood-mediated transport of toxicants through hepatic sinusoids, to enable quantitative, mechanistic prediction of hepatic dose-response for activation of the aryl hydrocarbon receptor toxicity pathway. Simultaneously, methods are being developing to extract quantitative maps of intracellular signaling and transcriptional regulatory networks perturbed by environmental contaminants, using a combination of gene expression and genome-wide protein-DNA interaction data. A predictive physiological model (DILIsym ${ }^{\mathrm{TM}}$ ) to understand drug-induced liver injury (DILI), the most common adverse event leading to termination of clinical development programs and regulatory actions on drugs, is also described. The model initially focuses on reactive metabolite-induced DILI in response to administration of acetaminophen, and spans multiple biological scales.

Keywords: systems toxicology, toxicity pathways, virtual liver, multi-scale modeling, drug toxicity, chemical toxicity, computational toxicology

\section{INTRODUCTION}

The 2007 report by the National Research Council (NRC) of the U.S. National Academies of Science, titled "Toxicity testing in the 21st Century: A Vision and A Strategy" (NAS/NRC, 2007), laid out a new path forward for the field of toxicology, envisioning an approach where most toxicity testing will be carried out in vitro, with a gradual reduction of reliance on high-dose animal studies. The basis of this risk assessment paradigm would be perturbation of cellular responses using a carefully selected suite of in vitro assays. Central to this vision is the idea of "toxicity pathways" innate cellular signaling pathways that are perturbed by chemicals and pharmaceuticals, and the determination of chemical concentration ranges where those perturbations are likely to be excessive, thereby leading to adverse health effects if present for a prolonged duration in an organism. A key element of the proposed approach is the use of computational systems biology models as a tool to generate hypotheses about cellular level dose-response based on existing data sets, and to identify data and knowledge gaps that can help guide the design of in vitro assays, focused animal studies, and improved in vitro - in vivo extrapolation (IVIVE) methods.

In 2009, the U.S. Environmental Protection Agency published its Strategic Plan for Evaluating the Toxicity of Chemicals (U.S.EPA, 2009), which also envisions dynamic mathematical modeling as a key component of risk assessment linking toxicity pathways to dose-response. This plan calls for computational models that can predict organ injury from chemical exposure through simulation of: (i) the dynamic characteristics of exposure and dose; (ii) perturbations to molecular pathways; (iii) the link between these perturbations and alterations to cell state; and (iv) integration of molecular and cellular responses into a physiological "virtual tissue" (U.S.EPA, 2009).

Here we provide an introduction to some concepts relevant to developing computational systems biology models of intracellular toxicity pathways for environmental chemicals and pharmaceuticals, with specific relevance to toxicity of the liver. The peroxisome proliferator-activated receptor (PPAR)- $\alpha$ nuclear receptor (NR) 
pathway in primary human hepatocytes is used as an example for computational reconstruction of a toxicity pathway network from genomic data. We then use the example of aryl hydrocarbon receptor (AhR) activation in the liver to outline the process of developing a multi-scale spatial model of the liver lobule and interactions among multiple hepatic cell types consequent to exposure to toxic agents. Finally, we outline a predictive physiological model $\left(\right.$ DILIsym $^{\mathrm{TM}}$ ) to understand drug-induced liver injury (DILI) in response to administration of acetaminophen, which spans multiple scales from the organ/tissue-level to the molecular and cellular levels. These varied modeling approaches, applied across different pathways and tissues, will be pivotal in creating twenty-first century in vitro toxicology testing strategies that are capable of determining likely pathway targets for chemicals and pharmaceuticals, and the risks associated with specific exposure and use conditions.

\section{TOXICITY PATHWAYS UNDERLYING BIOLOGICAL RESPONSE TO CHEMICALS}

The biological effects of a drug or hazardous chemical (ligand) in individual cells are mediated by cell-membrane or cytosolic "receptor" molecules and downstream signaling and transcriptional networks, which together comprise intracellular toxicity pathways. Changes in the topology and dynamic behavior of these pathways subsequent to recognition of the external ligand account for the particular shape of the dose-response curve for specific phenotypic end points. A finite number of core "stress response pathways" mediate the response of cells to various chemical stimuli to maintain homeostasis, or to make specific cell-fate decisions such as proliferation, differentiation, or apoptosis (Simmons et al., 2009). Examples of stress response pathways include the oxidative stress response, heat-shock response, DNA-damage response, hypoxia, and endoplasmic reticulum stress pathways, all of which are present in all cell types of an organism, and feature a common architecture consisting of a transcription factor (TF), a "sensor," and a "transducer" (Figure 1A; Simmons et al., 2009). This suite of pathways is typically activated at concentrations of chemicals significantly lower than those that lead to adverse effects at the organism level, and can be assayed as a group to serve as predictors of potential cell damage (Kultz, 2005; Simmons et al., 2009). A second group of toxicity pathways is comprised of the signaling networks related to activation of specific endogenous receptor pathways, such as estrogen, androgen, and thyroid hormone signaling. Overstimulation or inhibition of these diverse pathways can lead to toxic outcomes.

The canonical toxicity pathways discussed above are in turn made up of a core set of functional regulatory network motifs that underlie cellular homeostasis and fate decisions including phenotypic transitions (Alon, 2007). Each of these regulatory motifs, originally discovered from detailed investigation of transcriptional regulatory networks in the bacterium Escherichia coli (Shen-Orr et al., 2002) and the budding yeast Saccharomyces cerevisiae (Lee et al., 2002), has a characteristic structure and the capacity to perform specific information-processing functions (Bhalla and Iyengar, 1999; Tyson et al., 2003; Alon, 2007; Figure 1B). Some examples of response motifs are:

(i) negative feedback, which enables homeostasis and acceleration of response time in gene circuits (Rosenfeld et al., 2002; Zhang and Andersen, 2007);

(ii) positive feedback, which generates switching behavior between multiple phenotypic states (Ferrell, 2002);

(iii) the coherent feed-forward loop, which can introduce a time delay in activation as well as detect persistence in the activating signal (Mangan et al., 2003); and

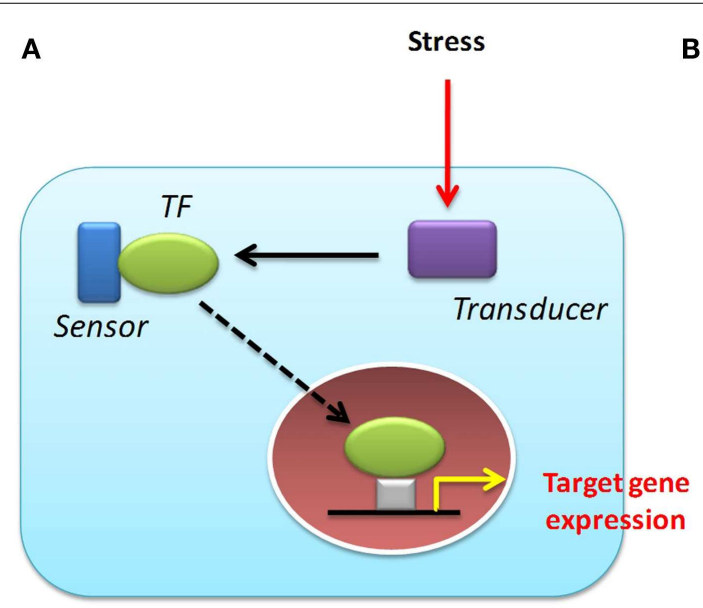

FIGURE 1 | Stress response pathways and network response motifs. (A) Typical structure of a stress response pathway (adapted from Simmons et al., 2009). Canonical stress response pathways, conserved broadly across eukaryotes, have a common structure for sensing damage and launching a transcriptional response to counteract the stress. (B) Common network motifs in intracellular response pathways. Three elements (genes/proteins) $X$, $Y$, and $Z$, in a pathway can regulate each other to form: (a) a coherent

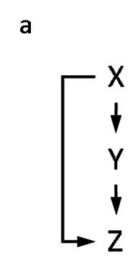

C

b

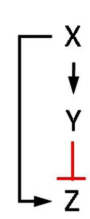

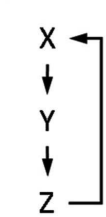

d

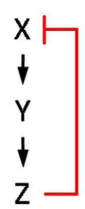

e

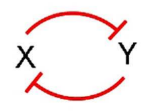

f

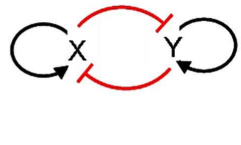

feed-forward loop where $X$ activates $Y$, and both $X$ and $Y$ activate $Z$; (b) an incoherent feed-forward loop where $X$ activates both $Y$ and $Z$, but $Y$ suppresses Z; (c) a positive feedback loop; and (d) a negative feedback loop. Two transcription factors $X$ and $Y$ can regulate each other through, for instance: (e) a double-negative feedback loop; or (f) a double-negative feedback loop with positive autoregulation. Sharp arrows denote activation; flat arrows denote suppression. 
(iv) the incoherent feed-forward loop, which can function as a pulse generator and response accelerator (Mangan et al., 2003, 2006).

These motifs often occur in combination to generate more complex regulatory patterns in transcriptional networks (Alon, 2007). Response motifs have been identified not just in unicellular organisms but also in the cells of higher organisms - for example in the circuits that control gene expression in the pancreas and the liver (Odom et al., 2004) as well as the regulatory circuits of human embryonic (Boyer et al., 2005) and hematopoietic (Swiers et al., 2006; Rothenberg, 2007) stem cells. Perturbation of these regulatory motifs is likely to be a key element of toxic response, and a better understanding of their organization and dynamic behavior should lead to improved prediction of the cellular outcome of specific perturbations introduced by various chemicals.

\section{COMPUTATIONAL SYSTEMS BIOLOGY MODELS TO UNDERSTAND PERTURBATIONS IN TOXICITY PATHWAYS}

Detailed characterization of molecular signatures associated with cellular perturbation of key toxicity pathways and disease states has been made possible by the advent of the "-omics" era. However, these molecular signatures do not by themselves translate to a clear causal network of pathway perturbation. Rigorous quantitative analysis of specific pathways and network motifs derived from these large-scale molecular signatures will aid mechanistic understanding of the underlying biological processes (Araujo et al., 2007). In particular, understanding the dynamic, dose-dependent behavior of toxicity pathways will require stimulation of these pathways at a number of time points and at various concentrations of the activating chemical, rather than static snapshots of the molecular state (Danna and Nolan, 2006).

Computational systems biology pathway (CSBP) models can play a key role in this process, allowing mechanistic prediction of the dose-response based on pathway dynamics (Zhang et al., 2010a). These models will have to be based on molecular circuits responsible for the basal operation of normal cellular pathways in the absence of an external chemical stressor, which sets up the background state from which additional perturbations will occur as the stressor level increases. A properly implemented CSBP model would take such changes into account to predict the range of concentrations of stressors that would not produce appreciable adversity. A key aspect of the applicability of such models is the quantitative characterization of the underlying molecular circuits from appropriately designed in vitro assays. CSBP models can also allow the assessment of pathway components that display polymorphisms in the human population to help identify sensitive subpopulations.

Deterministic simulations based on ordinary differential equations (ODEs) are a common approach to modeling dynamical systems like intracellular signaling circuits. An assumption with deterministic ODE models is that the molecular components of the network of interest exist in a well-mixed volume such as the cytosol or nucleus, and that the amounts or concentrations of all molecular species in the network can be approximated by continuous variables. A typical deterministic model consists of a set of coupled ODEs, each describing the rate of change in the concentration or abundance of a molecular component, and incorporating terms that account for the known biochemical interactions among the various molecular species (Aldridge et al., 2006). The numerical values of parameters and initial conditions are assigned based on existing literature and in vitro data, and the time course of the system is simulated using one of a variety of numerical ODE solvers. Parameter assignment is not always a straightforward exercise: experimental data is often not available for the particular species or cell type being modeled. In such cases, parameter estimation techniques need to be applied (Swameye et al., 2003). Parameter uncertainty, distinct from biological variability, can cause uncertainties in prediction from a computational model (Vanlier et al., 2012). Although this ODE-based approach does not take into account either spatial diffusion or noise in gene expression, it is a valuable computational tool that has provided many insights into the design and function of molecular circuits underlying a number of biological processes like cell cycle regulation, signal transduction, cell differentiation, stress response, and biological rhythms (Carrier et al., 1995; Bhalla et al., 2002; Forger and Peskin, 2003; Novak and Tyson, 2003; El-Samad and Khammash, 2006; Bhattacharya et al., 2010).

Stochastic fluctuations in gene expression and levels of intracellular molecular species, which are ignored in the ODE-based deterministic modeling approach, can play an important role in cellular response by generating non-genetic phenotypic variability among an isogenic cell population (Kaern et al., 2005; Losick and Desplan, 2008; Pearson, 2008). The random fluctuations in mRNA and protein concentrations can be modeled by stochastic simulation algorithms like Gillespie's direct method and first-reaction method (Gillespie, 1976, 1977). Gillespie's algorithm is essentially a Monte Carlo simulation technique where the number of reacting molecules in the model system and the reaction rate constants are used to generate two probability density functions, one of which predicts the time interval between successive reaction events, and the other identifies which one among all possible reactions is likely to occur next. The time variable in the simulation is then updated by the calculated time interval, and the copy numbers of the reactants and products of the predicted reaction are updated according to the reaction stoichiometry. Several modified versions of the original Gillespie algorithm have been developed to improve its computational efficiency, including the next reaction method, tau-leaping, and hybrid models (Gibson and Bruck, 2000; Gillespie, 2000; Rathinam et al., 2003; Salis and Kaznessis, 2005). Most of these are approximate methods that greatly reduce the simulation time. In some cases, stochastic simulations simply add "white noise" terms to the most variable species in ODE equations. Applications of stochastic modeling tools include investigation of oscillatory patterns in protein levels (Proctor and Gray, 2008) and cellular differentiation (Zhang et al., 2010b).

Developmental processes are usually driven by discrete, all-ornone changes in the expression of lineage-specific genes belonging to a large gene regulatory network. The Boolean network modeling paradigm, where each variable (gene) is assumed to take either of two values, 0 (off) and 1 (on), is often a good approximation of the gene expression patterns in these processes. The state of each gene is updated according to its current state and that of other regulatory genes it is connected to in the network, as governed by a preset Boolean logical rule table. This binary-state 
assumption reduces the dependence on various kinetic parameters in the model, instead making full use of the large available database of qualitative protein-protein and protein-gene interactions. As with deterministic and stochastic models, a simulation of a Boolean network model should converge to an attractor state representing the binary gene expression pattern of a particular phenotypic state (Albert and Othmer, 2003). For chemicals that exhibit developmental toxicity, a Boolean network model can be used to predict low-dose effects based on high-throughput screening, allowing comparison of gene expression profiles between the undisturbed and disrupted states of the transcriptional regulatory network (Jack et al., 2011).

These various modeling techniques are based on a topological representation of cellular signaling networks, and ignore the spatial relationship among intracellular molecular species and the spatial heterogeneity inside a cell. In reality, the cytosol, the nucleus and organelles such as mitochondria and endoplasmic reticulum segregate the intracellular space into a number of discrete compartments. The difference in concentrations of molecules between these compartments and inter-compartment molecular traffic can be accounted for by simple compartmental models, where each subcellular compartment is assumed to behave as a well-mixed sub-system. However, diffusion must be explicitly considered in cases where the spatial aspect of molecular diffusion within cellular compartments becomes rate-limiting. Examples include pattern formation in the animal body in response to concentration gradient of morphogens, effects of chemicals on different dermal layers when absorbed by the skin, and propagating waves of signaling molecules in the cytosol. In these circumstances, spatiotemporal models based on partial differential equations may be employed (Kholodenko, 2006; Kholodenko et al., 2010). The spatial dimension can also be explicitly incorporated by modeling the motion and interaction of distinct molecular species as discrete particles, for example with agent-based spatial modeling approaches. Agent-based models also address another problem arising from the lack of a spatial component in network models: incorporating multicellular or tissue-level interactions.

\section{THE AGENT-BASED MODELING APPROACH}

Agent-based modeling (ABM), also referred to as "individual-based modeling" (Bonabeau, 2002; Grimm et al., 2005; An et al., 2009) is a more intuitive approach than traditional equation-based modeling formalisms, and as such can be helpful in model development, model interpretation, and model use by a variety of stakeholders. The "agents" in an ABM may be individual molecules, cells, or other entities that populate a virtual "world" (a discrete lattice), with each agent represented as a distinct data structure (or "object") in the computational model (see Figure 2). Agents can move in the physical space of the world, and interact with neighboring agents according to a pre-defined set of rules. As the model is simulated over a large number of iterations, these local interactions generate macroscopic, sometimes counterintuitive, phenomena of interest - referred to as "emergent properties" of the system being modeled.

Agents in an ABM are modeled as discrete entities located in a physical space - thus it is no longer necessary to assume a well-mixed continuous system as in differential equation-based dynamic modeling approaches. The reliance on averaged aggregate parameters is therefore reduced in favor of an emphasis on strict definition of rules governing agent behavior and interactions. Decisions regarding such explicit rules for agent behavior are typically more intuitive than the choice and estimation of abstract parameters in equation-based models, making it easier for decision-makers to interpret and use the model. ABM platforms like NetLogo (http://ccl.northwestern.edu/netlogo/) use an integrated visualization/programing interface (Figure 2), which makes it straightforward to evaluate the effect of modifications to the "engine" of the model on model behavior.

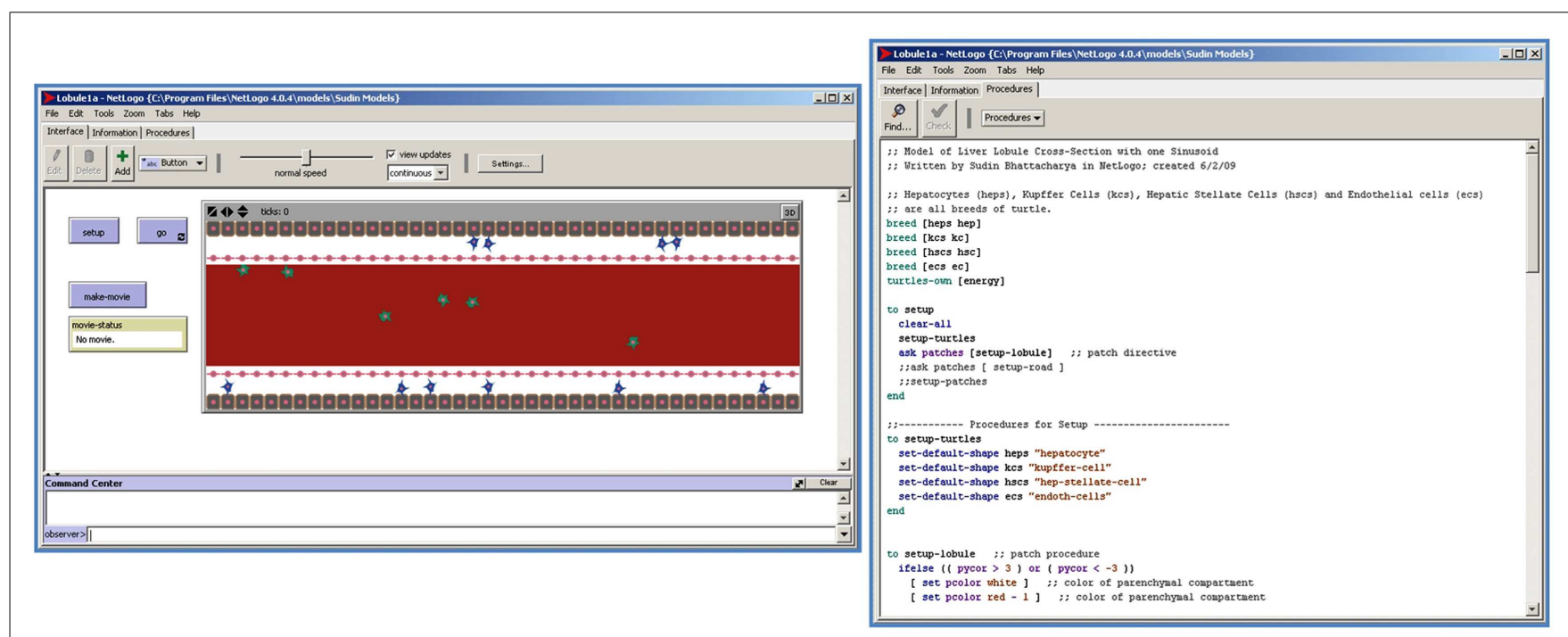

FIGURE 2 |The NetLogo agent-based modeling platform with an integrated visualization/programing interface. "Agents" occupy a virtual spatial "world" in this two-dimensional representation of the liver lobule (left). The programing interface (right) in NetLogo makes it simple to test various changes in model code during model development. 
Agent-based modelings were first used in models in social science and ecology, but have been applied to a wide range of biological problems in recent years, particularly for modeling pathophysiological processes with a significant spatial component (An et al., 2009). These include tumor formation (Engelberg et al., 2008; Gerlee and Anderson, 2009; Zhang et al., 2009b,c), inflammation (An, 2001, 2008), wound healing (Walker et al., 2004; Vodovotz, 2006; Sun et al., 2007), T-cell activation and proliferation within a lymph node (Bogle and Dunbar, 2010), and stromal cell trafficking during acute skeletal muscle ischemia (Bailey et al., 2009). Agents in these "virtual tissue" models represent the behavior of individual cells - the natural functional unit in tissue-level biological phenomena. In the toxicology context, virtual tissues can be thought of as multicellular models of tissue microenvironment that attempt to reconstruct the in vivo milieu of target organs to simulate the physiological consequences of toxicity pathway activation by specific chemicals. As such they represent an extension of traditional compartmental models to the scale of individual cells in a tissue (Shah and Wambaugh, 2010).

\section{LIVER MODELING CASE STUDIES CASE STUDY 1: A CSBP MODEL: CAUSAL TRANSCRIPTIONAL NETWORK INFERENCE}

The 2007 NAS report (NAS/NRC, 2007) emphasized computational modeling of core intracellular toxicity pathways as a crucial component of the new toxicity testing paradigm. While these pathways have been the object of a large number of experimental studies, the causal molecular networks giving rise to activation of the pathways have not been mapped out in sufficient detail. Here we describe an approach for causal network mapping we are currently applying to the analysis of two prototype toxicity pathways: the PPAR $\alpha$ pathway in liver parenchymal cells, and the estrogen receptor pathway in uterine epithelial cells. Such approaches are likely to be pertinent to mapping the pathways activated by a broad group of toxicants.

Both ER and PPAR $\alpha$ belongs to the NR family: ligand-activated TFs that regulate a variety of physiological functions involved in development, metabolism, and homeostasis. These include the steroid hormone-receptors: estrogen receptor, androgen receptor (AR), glucocorticoid receptor (GR), and progesterone receptor (PR), as well as the PPARs, liver $\mathrm{X}$ receptors (LXRs), retinoic acid receptors (RARs), and retinoid X receptors (RXRs). NRs act on chromatin combinatorially and dynamically throughout the genome to regulate transcriptional responses to physiological and environmental stimuli (Carlberg and Seuter, 2010; George et al., 2011).

The PPARs function as regulators of hepatic lipid metabolism and adipogenesis (Kersten et al., 2010; Pyper et al., 2010; Siersbæk et al., 2010). They form heterodimers with RXR and bind to peroxisome proliferator response elements (PPREs) on the promoters of target genes to induce gene expression. There are three identified PPAR isotypes $\alpha, \beta$, and $\gamma-$ among which PPAR $\alpha$ regulates genes involved in fatty acid oxidation, ketogenesis, gluconeogenesis, cholesterol catabolism, and lipoprotein metabolism (Mandard et al., 2004; Lefebvre et al., 2006), as well as anti-inflammatory response (Zandbergen and Plutzky, 2007; Michalik and Wahli, 2008). Sustained PPAR $\alpha$-mediated induction of peroxisome proliferation can produce liver tumors in rats and mice (Reddy et al., 1976, 1980).

In the canonical picture, activation of PPAR $\alpha$ in liver parenchymal cells causes downstream alterations in gene expression through a series of coordinated steps:

(i) phosphorylation of PPAR $\alpha$ in the cytosol;

(ii) translocation of $\operatorname{PPAR} \alpha$ to the nucleus;

(iii) heterodimerization with its binding partner retinoid $\mathrm{X}$ receptor alpha $(\mathrm{RXR} \alpha)$;

(iv) binding of the heterodimer at DNA-response-elements (PPREs) in the promoters of target genes; and

(v) alterations in binding of co-activators and co-repressors.

In recent years, genome-wide profiling of TF-binding activity has provided an unprecedented global picture of gene regulation. Chromatin immunoprecipitation (ChIP) in combination with microarray hybridization (ChIP-chip) or high-throughput sequencing (ChIP-seq) has been widely used for genome-wide location analysis and characterization of TF-chromatin interactions both for NRs and other TFs (Odom et al., 2004; Carroll et al., 2005; Bieda et al., 2006; Gao et al., 2008; John et al., 2008; Lefterova et al., 2008; Nielsen et al., 2008; Fullwood et al., 2009; Delacroix et al., 2010; Hu et al., 2010; Ravasi et al., 2010; van der Meer et al., 2010; Dere et al., 2011). An important finding of these studies is the combinatorial control of gene expression by NRs. TF-binding sites are often clustered in the genome, which allows coordinated action of multiple TFs to induce or suppress the expression of individual genes in a cell type and condition-specific manner (George et al., 2011).

In addition, gene regulation by "DNA-independent" chromatin$\mathrm{NR}$ interactions is surprisingly common across the genome (George et al., 2011), whereby NRs indirectly modulate transcription by "tethering" to other TFs directly bound to DNA. About $25 \%$ of ER and $30 \%$ of GR binding to the chromatin, for example, appears to be DNA-independent - possibly enabled by tethering to co-localized TFs like RUNX1 and AP1 (Heldring et al., 2007; So et al., 2007; Reddy et al., 2009; Stender et al., 2010). Although the number of potential NR binding sites across the genome is vast, only a small fraction of these sites is occupied, with an even smaller number of sites likely contributing to functional gene regulation in vivo (Bourdeau et al., 2004; Carroll et al., 2005, 2006). These observations suggest that a more realistic picture of NR-mediated gene regulation can be obtained by combining gene expression data from transcriptome profiling with genome-wide analysis of NR localization.

Accordingly, we are using a combination of: (i) microarraybased gene expression data; (ii) published ChIP-on-chip analyses of genome-wide NR binding; and (iii) curated lists of directly bound NR target genes to develop a comprehensive picture of NRmediated transcriptional regulation. Differentially expressed genes responding to specific NR ligands are classified into three groups:

(i) genes with the NR directly bound to their promoters;

(ii) genes with the NR indirectly bound to their promoters by tethering to other directly bound TFs

(iii) non-NR-bound genes regulated by other TFs. 
The non-NR TFs that regulate genes in groups (ii) and (iii) are identified from the TRANSFAC (Biobase Corporation, Beverly, MA, USA) database of TF-DNA interactions. These transcriptional interactions may be summarized in a "latent regulatory network" ( shown schematically in Figure 3A), which could potentially reveal the significant regulatory hubs in the transcriptional network. Superposition of gene expression results from microarray studies onto the latent network then allows visualization of timeor dose-dependent transitions in the network (Figures 3B-D). This derivation focuses purely on regulation at the transcriptional level, and as such ignores epigenetic-level regulations including post-translational modifications of NRs that could be important in certain dosing contexts.

\section{CASE STUDY 2: AGENT-BASED MODEL OF THE HUMAN LIVER Motivation for multi-scale, agent-based models of the liver}

Multi-scale spatial models based on the ABM formalism are particularly suited for investigating the effects of toxic chemicals and drugs in the liver, which arise from a combination of cellular and tissue-level mechanisms, with marked heterogeneities observed across the liver lobule. These mechanisms are discussed below in the context of dioxin-induced liver toxicity - a particularly well-studied phenomenon.

The persistent environmental contaminant 2,3,7,8-tetrachloro dibenzo-p-dioxin (TCDD) belongs to a class of toxicants known as halogenated aromatic hydrocarbons (HAHs). The toxic effects of HAHs in mammals are mediated through binding to the AhR (Poland and Knutson, 1982; Schmidt and Bradfield, 1996; Rowlands and Gustafsson, 1997). The liver is one of the most sensitive organs for toxicity induced by TCDD. A spatial agent-based "virtual tissue" model of the liver lobule that incorporates a mechanistic representation of the activation of the AhR toxicity pathway in individual hepatocytes can be used to investigate the sequence of events leading from early activation of the AhR pathway through subsequent cellular effects to cell proliferation, and culminating in liver cancer as an endpoint. The structure of the AhR pathway is well-studied (Figure $\mathbf{4 A}$ ), and as such could serve as a good case study for multi-scale, quantitative dose-response model development based on information from in vitro assays and in vivo biomarkers.
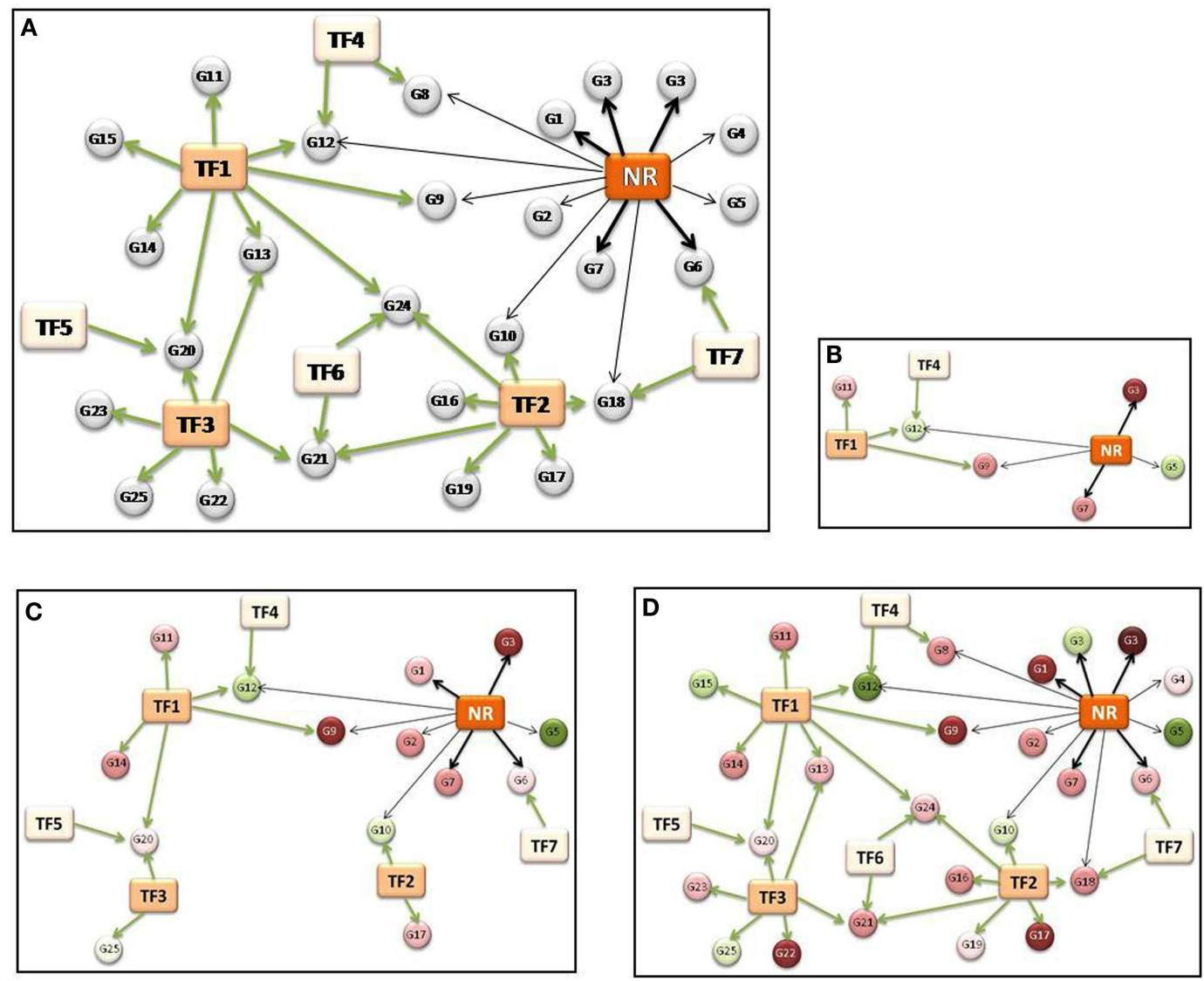

FIGURE 3 | Schematic representation of inferred nuclear receptor transcriptional regulatory network and dose-response. Rectangular nodes indicate regulatory transcription factors (TFs), with the functional nuclear receptor (NR) marked in dark orange. Each directed edge in the network indicates binding of a TF to the promoter of a target gene (circular nodes, G1-G25). Dark black arrows connect NR with direct targets; light black arrows with indirect targets. Green arrows connect other (non-NR) TFs with their target genes. (A) The "latent" network, showing well-connected transcriptional "hubs" (NR, TF1, TF2, TF3). (B-D) Evolution of network structure with increasing levels of stimulation with NR ligand. Target genes are colored by level of expression (red: upregulation; green: downregulation). 


\section{A}

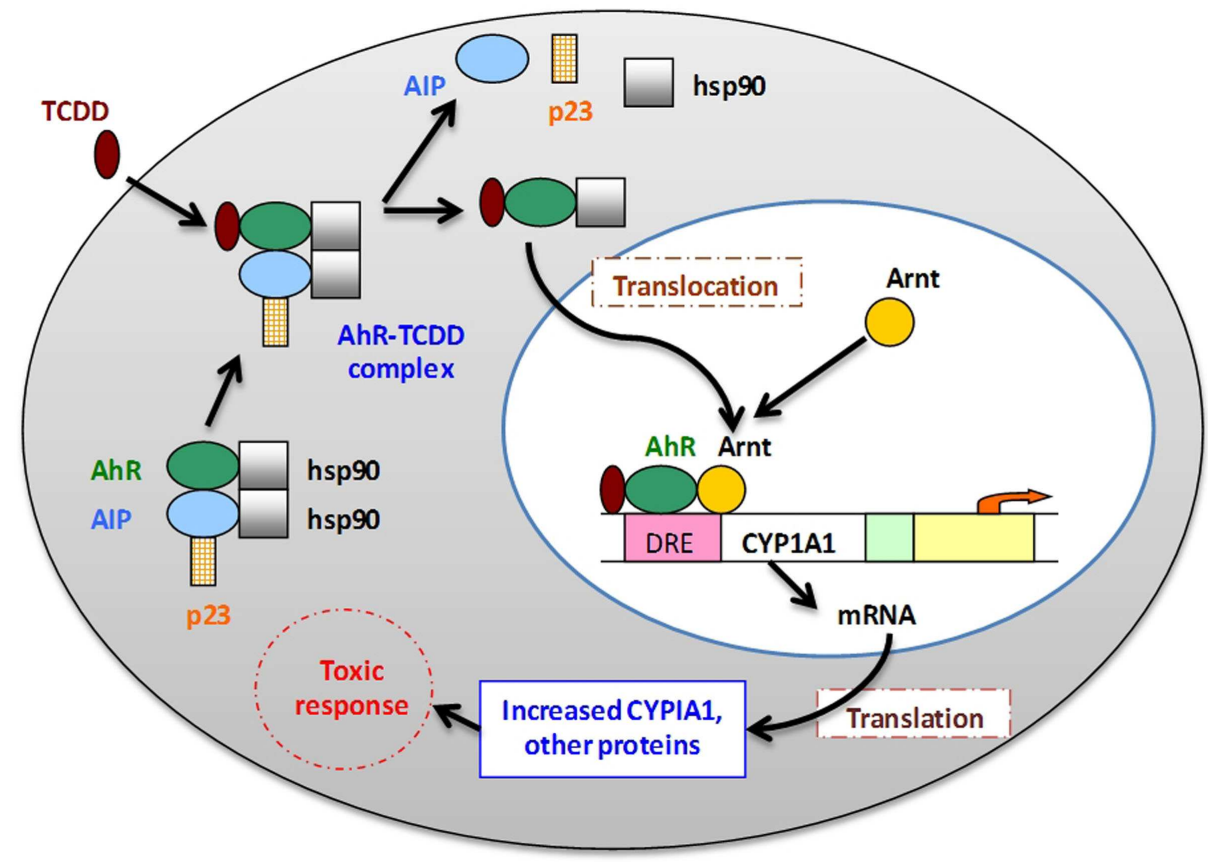

B

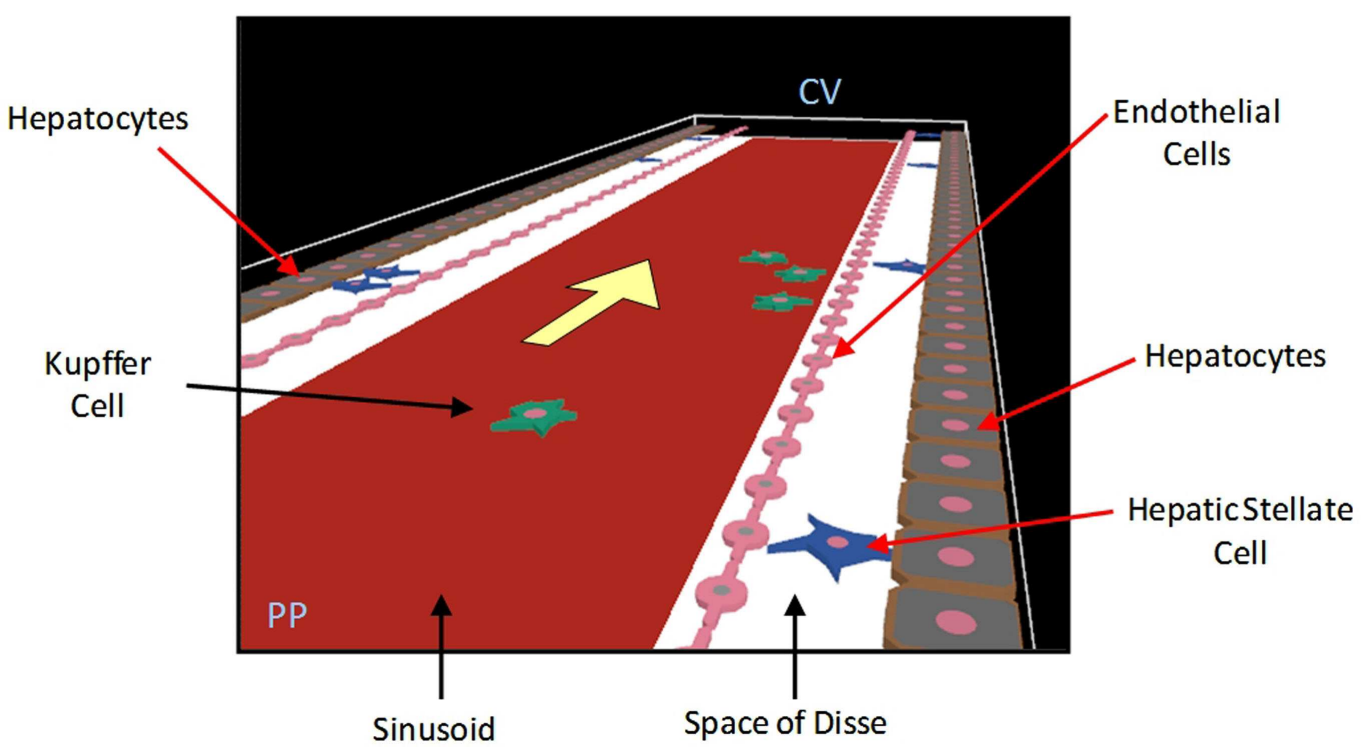

FIGURE 4 | The AhR signaling pathway, and agent-based spatial model of liver lobule. (A) Key components and events in AhR signaling pathway activation. AIP: Aryl hydrocarbon receptor interacting protein; hsp90: heat-shock protein 90; Arnt: aryl hydrocarbon receptor nuclear translocator; DRE: dioxin-responsive element. (B) Agent-based model of liver lobule section (representational unit: one sinusoid), incorporating hepatocytes, liver endothelial cells, hepatic stellate cells, and Kupffer cells.
The hepatic dose-response of TCDD culminating in liver cancer consists of the following key steps (Mills and Andersen, 1993):

(i) Accumulation of TCDD in the target tissue.

(ii) Formation of a complex with AhR.

(iii) Activation of growth-regulatory genes by the AhR-TCDD complex.

(iv) Cellular responses to the altered expression of growthregulatory gene products. (v) The effect of these cellular events on tumor promotion and progression.

However the mechanistic and causal links connecting steps (iii) through (v) are not well understood.

The carcinogenic effects of TCDD are believed to be mediated by tumor promotion rather than initiation (Pitot et al., 1980). A "negative selection" model of tumor promotion has been proposed where specifically mutated cells acquire a proliferative advantage in 
the presence of persistent mitosuppression (Andersen et al., 1995). TCDD suppresses apoptosis induced in rat hepatocytes by DNAdamaging agents, which could result in selective expansion of clones evading growth arrest and apoptosis (Worner and Schrenk, 1996; Bock and Kohle, 2005). The traditional benchmark dose calculation for low-dose hepatotoxic effects of TCDD is linked to centrilobular induction of cytochromes P450 1A1 (CYP1A1) and 1A2 (CYP1A2). However the relation between these early centrilobular gene expression events, and subsequent cell proliferation events likely originating in the periportal region of the liver lobule, is unclear. Specifically, cytochrome P450 activity and cell proliferation follow different dose-response patterns: CYP1A1 activity appears to be reversible following prolonged TCDD exposure, while the selective growth of altered hepatic foci and cell proliferation are persistent (Maronpot et al., 1993; Sewall et al., 1995; Tritscher et al., 1995; Whysner and Williams, 1996; Viluksela et al., 2000). Liver cytotoxicity may be an intermediate step in the sequence of cellular events leading to tumor promotion (Busser and Lutz, 1987; Maronpot et al., 1993; Whysner and Williams, 1996; Viluksela et al., 2000).

Putative liver stem cells - known as "oval cells" in the rat and "progenitor cells" in the human, may be one possible link between early events in AhR toxicity pathway activation and eventual cell proliferation culminating in liver cancer (Lemire et al., 1991; Libbrecht et al., 2001). These cells, which can differentiate into either hepatocytes or cholangiocytes (bile duct cells; Roskams et al., 2003), may have a role in development of human liver tumors (Libbrecht et al., 2001). In a quiescent or healthy liver, oval cells are localized in the Canals of Hering, situated in the smallest branches of the biliary tree close to the periportal end of the liver lobule (Fausto and Campbell, 2003; Fausto et al., 2006; Gaudio et al., 2009). However in the diseased human liver, in the case of both hepatitis (Libbrecht et al., 2000) and hepatocellular adenomas (Libbrecht et al., 2001), progenitor cells and hepatocyte-like cells are found scattered throughout the parenchyma, suggesting migration and differentiation toward the hepatocyte lineage. Intriguingly, biopsies of human primary liver tumors have revealed cells with an intermediate phenotype between that of hepatocytes and bile duct cells, suggesting the involvement of these liver progenitor cells (Robrechts et al., 1998; Kim et al., 2004).

The Hippo signaling pathway regulates cell contact inhibition and suppression of hepatic oval cell proliferation (Zeng and Hong, 2008; Lee et al., 2010). Interestingly, TCDD activates the protooncogene cyclin A to deregulate contact inhibition in rat liver oval cells (Weiss et al., 2008), providing a possible role for this pathway in TCDD-induced tumor promotion. Several other nonparenchymal cells (e.g., hepatic stellate cells and Kupffer cells) also regulate oval cell activity (Zhang et al., 2009a). Livers of rats treated with TCDD and other AhR agonists exhibit loss of cell-cell contact and enhanced cell proliferation including oval cell hyperplasia (Chramostová et al., 2004; NTP, 2006a,b; Andrysík et al., 2007; Dietrich and Kaina, 2010).

In spite of the large number of empirical studies with TCDD, some of which are summarized above, there is no agreement on a unifying hypothesis to connect these observations into a mechanistic description linking AhR toxicity pathway activation to liver cancer. Spatial multicellular ABM of the liver lobule incorporating parenchymal (hepatocytes) and non-parenchymal cells (hepatic stellate cells and Kupffer cells), along with oval cell proliferation, can serve as an ontological tool to assemble diverse in vitro and in vivo observations and compare alternative hypotheses for TCDD-induced tumor promotion. Research teams at The Hamner are pursuing multi-scale modeling approaches for examining pathways perturbed by TCDD and other environmental chemicals, as well as therapeutic molecules that cause DILI.

\section{The liver ABM}

A realistic spatial model of the liver lobule and drug/chemicalinduced toxic effects needs to account for:

(i) cellular heterogeneity across the lobule;

(ii) multiple cell types in the liver lobule that participate in liver injury.

The virtual tissue formalism can be used to develop a spatial agent-based model of the human liver lobule (the "lobule ABM"), with individual hepatocytes represented by single agents. There have been some initial efforts toward development of agent-based representations of the liver (Hunt et al., 2006; Davila and An, 2010; Wambaugh and Shah, 2010). Here we lay out the steps toward developing a multi-scale model, where the lobule ABM is coupled with an intra-hepatocyte ODE-based kinetic model of AhR pathway activation for dose-response prediction with TCDD or other chemicals (Figures 5A-C). A preliminary version of such a model, incorporating hepatocytes, liver endothelial cells, hepatic stellate cells, and Kupffer cells, is shown in Figure 4B. Other components, including oval cells, will be added in course of model refinement.

(i) Output from a standard TCDD physiologically based pharmacokinetic (PBPK) model (e.g., Leung et al., 1988, 1990) estimates disposition of TCDD in the liver lobule: the input dose for the lobule ABM (Figure 5A).

(ii) This TCDD input dose acts upon the individual agents (hepatocytes) in the model, which occupy heterogeneous states by virtue of differential gene expression: e.g., graded expression of the Ah receptor along the lobule (higher at the centrilobular end; Lindros et al., 1997; Figure 5B).

(iii) The agents (hepatocytes) are implemented as intracellular signaling cascades: i.e., key molecular events associated with the AhR toxicity pathway (Figures $4 \mathrm{~A}$ and $5 \mathrm{C}$ ). Individual signaling events along the cascade can be modeled and quantitatively calibrated from the literature, including TCDD-AhR binding (Poland and Knutson, 1982), TCDDAhR-ARNT binding (Rowlands et al., 1996; Rowlands and Gustafsson, 1997), activation of AhRR (AhR repressor) by liganded AhR and reciprocal inhibition of AhR binding activity by AhRR (Mimura et al., 1999; Evans et al., 2008), and cytochrome (CYP) P450 protein induction (Jones et al., 1985; Fisher et al., 1989; Nebert et al., 2004).

Subsequent steps incorporate additional events into the signaling cascade shown in Figure 5C, for example crosstalk between the AhR and cell cycle/cell proliferation pathways (Elferink, 2003; Dietrich and Kaina, 2010). The tissue-level model implements specific "agent rules," e.g., hepatocyte proliferation (agent 


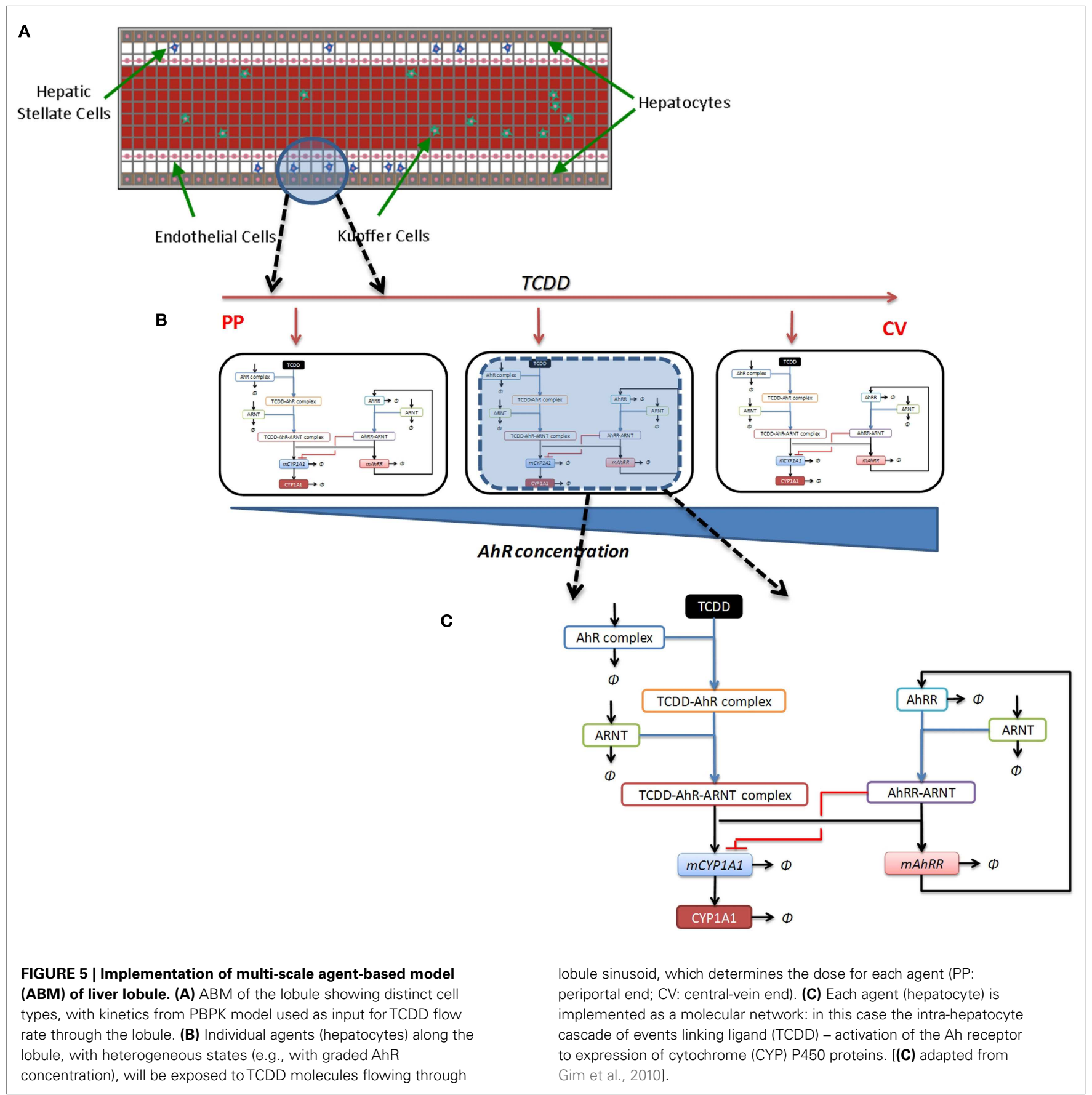

addition), or hepatocyte death (agent deletion), at specific levels of TCDD, or downstream signaling components/metabolites. The model structure would be extensible to other chemicals besides TCDD; however the implementation of the agent structure (i.e., the signaling cascade shown in Figure 5C) will vary from case to case, depending on the specific toxicity pathways stimulated. In addition, a variety of interactions between diverse cell types/agents will be specified to account for pharmacodynamic responses, including necrosis, apoptosis, proliferation, and tumor promotion.

\section{CASE STUDY 3}

\section{ODE-based mechanistic multi-species model of the liver}

Drug-induced liver injury is the most common adverse drug event leading to termination of clinical development programs and regulatory actions on drugs, as well as the most common cause of acute liver failure in the United States (Ostapowicz et al., 2002). The DILI-sim Initiative is a partnership of several drug development companies, led by The Hamner Institutes for Health Sciences, to improve prediction and understanding of DILI. The DILIsim Initiative sponsors the development and application of the 
DILIsym $^{\mathrm{TM}}$ model, a computational representation of physiological processes involved in DILI. The model (Howell et al., 2012; Woodhead et al., 2012) initially focuses on reactive metaboliteinduced DILI and spans multiple scales of physiology, from the organ/tissue-level to the molecular and cellular levels (Figure 6). The DILIsym ${ }^{\mathrm{TM}}$ model utilizes ODEs in the MATLAB computing platform (The MathWorks, Natick, MA, USA). Multiple submodels are included: (a) PBPK dynamics, (b) glutathione (GSH) depletion and synthesis, (c) mitochondrial dysfunction, (d) the hepatocyte life cycle and cell death due to ATP depletion and mitochondrial dysfunction, (e) the innate immune response, and (f) clinical endpoints, e.g., bilirubin, alanine aminotransferase (ALT), and keratin 18. Using publicly available literature, the DILIsym ${ }^{\mathrm{TM}}$ model includes parameters to represent mouse, rat, and human physiology which enables species-specific investigation and facilitates cross-species interpretation. Further, a genetic algorithm has been applied to create alternate parameterizations of the model within each species. These alternate parameterizations, termed SimPops ${ }^{\mathrm{TM}}$, are generated to explore inter-individual differences in response with respect to DILI. Simulated protocols run in the
SimPops ${ }^{\mathrm{TM}}$ framework allow the researcher to assess whether and how variation in the underlying biology impacts the predicted outcomes. The model integrates available mechanistic data on DILI to recapitulate in vivo responses using only in vitro data, and to identify critical drug-related uncertainties that if resolved could vastly improve the understanding and/or treatment of drug hepatotoxicity. The following examples illustrate the application of the DILIsym ${ }^{\mathrm{TM}}$ model to understand DILI induced by acetaminophen (APAP) and methapyrilene (MP).

Acetaminophen metabolism via the cytochrome P450 system (Cyp450) yields the toxic reactive metabolite, $N$-acetyl- $p$ benzoquinone imine (NAPQI). As GSH concentration is depleted, NAPQI forms protein adducts and induces mitochondrial oxidant stress, leading to cell death. The DILIsym ${ }^{\mathrm{TM}}$ model includes the basic biochemistry to describe these processes, and model simulations are consistent with molecular data, e.g., changes in liver GSH following APAP administration (Figure 7), and the corresponding circulating indicators of liver injury, e.g., ALT (Figure 8). Formalizing the available literature in the DILIsym ${ }^{\mathrm{TM}}$ model has itself provided insights into the underlying biology. For example,

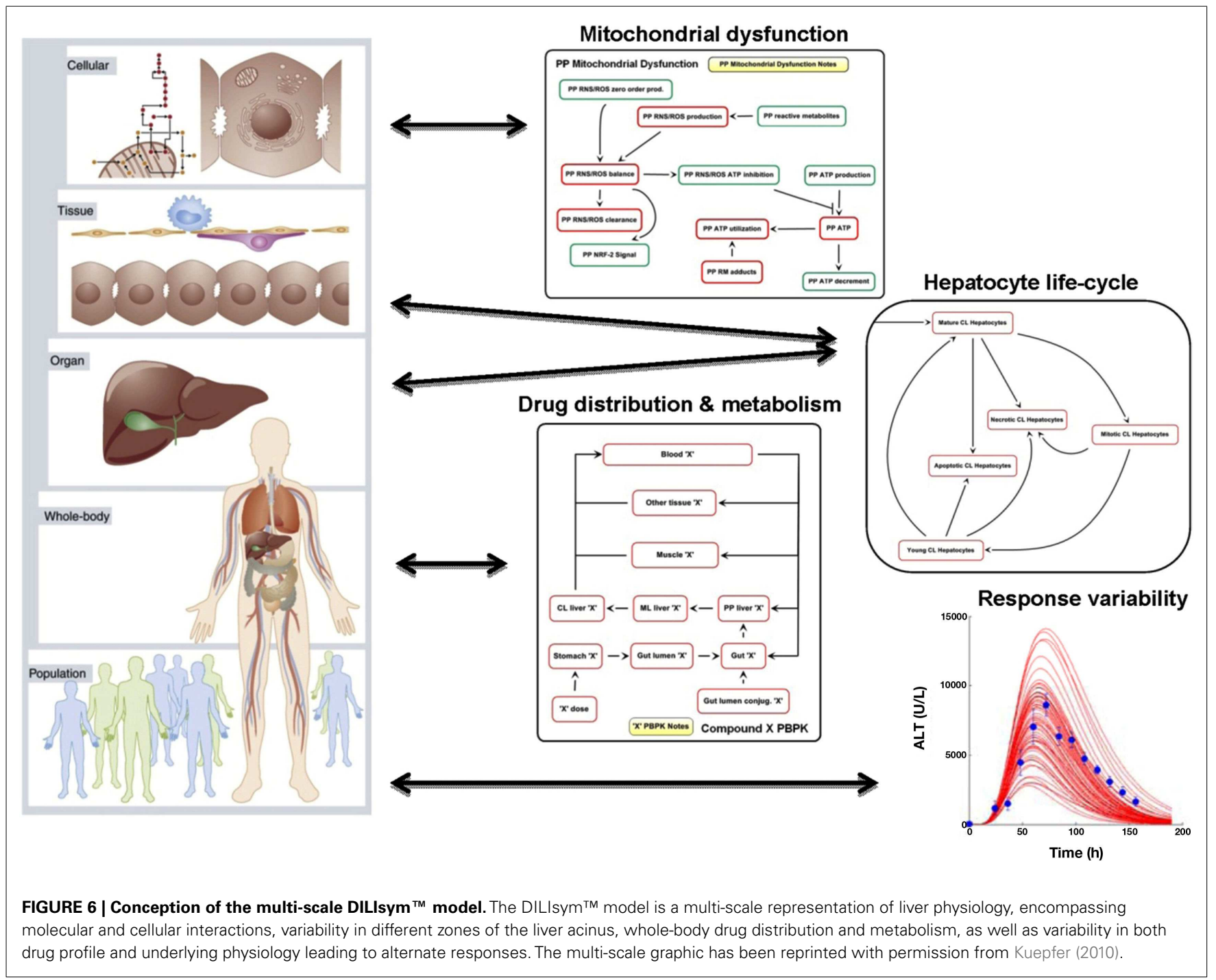




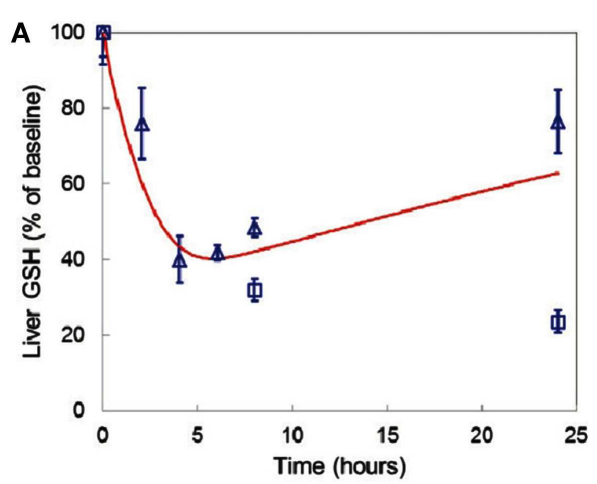

FIGURE 7 | Simulations from the DILIsym ${ }^{\mathrm{TM}}$ model are compared against published data on the underlying biology as illustrated in the GSH example. (A) The baseline simulated rat administered $500 \mathrm{mg} / \mathrm{kg}$ APAP was evaluated for degree and kinetics of GSH depletion against data from Chen et al. (2009) (squares) and Vendemiale et al. (1996) (triangles). (B) A genetic

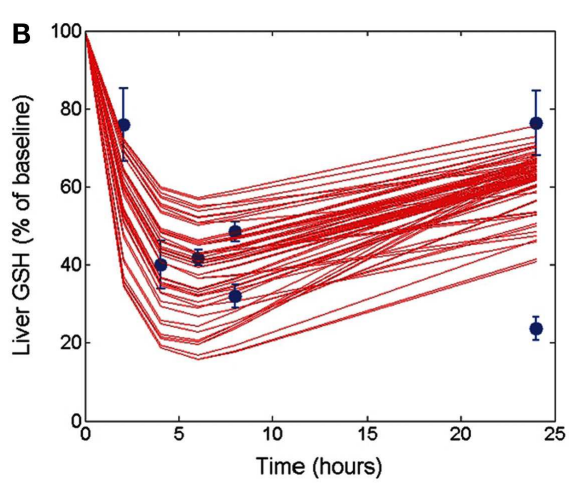

algorithm was applied to created alternate simulated rats with variability in multiple parameters. Results from alternate simulated rats administered $500 \mathrm{mg} / \mathrm{kg}$ APAP were compared against the same data (circles for all data points). Alternate simulated rats reflect reported biological variability and permit testing of how such biological variability impacts outcomes.

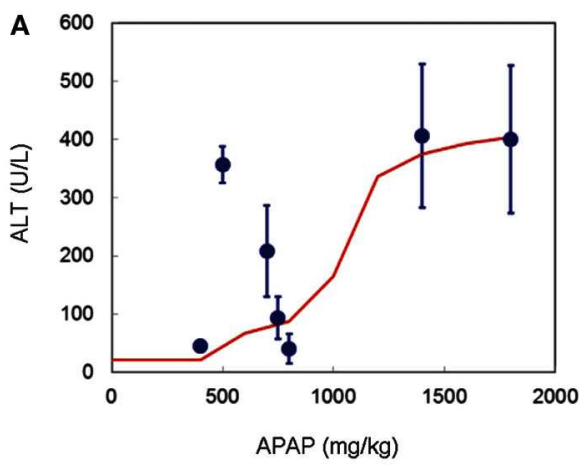

FIGURE 8 | Simulations from the DILIsym ${ }^{\mathrm{TM}}$ model are compared against published data on indicators of liver damage in response to APAP. (A) Results from the baseline simulated rat administered different doses of APAP was evaluated for ALT elevation against data from multiple references (Zieve et al., 1985; Chanda et al., 1995; Sugimura and

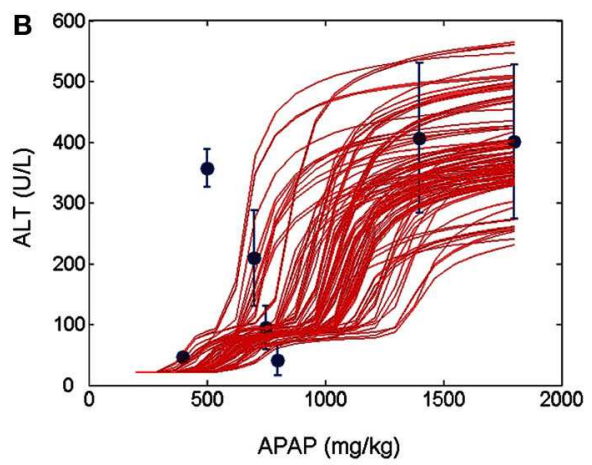

Yamamoto, 1998; Wang et al., 1999; Waters et al., 2001; Gueguen et al., 2007; Chen et al., 2009; all data in circles). (B) Results from alternate simulated rats administered different doses of APAP were compared against the same datasets. Alternate simulated rats reflect reported variability in liver damage following APAP administration. the modeling team sought to examine Hy's Law which specifies liver injury concerns in subjects with simultaneous elevations of ALT exceeding three times the upper limit of normal (ULN) and of bilirubin exceeding twice the ULN. Bilirubin is inversely correlated with viable hepatocyte numbers (Portmann et al., 1975). However bilirubin is elevated before liver necrosis is apparent (Zieve et al., 1985; Sawant et al., 2004; Pooranaperundevi et al., 2010a,b), suggesting that hepatocyte death may not be the primary mechanism underlying early increases in bilirubin. Alternate mechanisms for drug-induced loss of hepatocellular function were investigated. While analyzing these data, we observed an inverse correlation between GSH and bilirubin following drug administration (Sawant et al., 2004; Pooranaperundevi et al., 2010a,b). In addition, there is a direct correlation between hepatic GSH and ATP levels (Jenner and Timbrell, 1994). Together, these data indicate that drug-induced bilirubin elevation might initially result from a decrease in hepatocellular ATP. Bilirubin processing includes several steps that are likely ATP-dependent, e.g., bilirubin conjugation and export from the hepatocyte (Tiribelli and Ostrow, 1996; Paulusma et al., 1997; Borst et al., 2007). Using the DILIsym $^{\mathrm{TM}}$ model, APAP was simulated in the presence or absence of an ATP contribution to bilirubin generation. The addition of an ATP effect more faithfully reproduces experimental data on drug-induced early bilirubin elevation than drug-induced hepatocyte death alone (Figure 9A), and inclusion of an ATP effect does not compromise consistency with the data relating hepatocyte numbers to bilirubin (Figure 9B). This example illustrates the integration of multiple datasets and the manner in which it supports the formulation of new hypotheses that better reconcile the data.

The DILIsym ${ }^{\mathrm{TM}}$ model also allows protocol optimization. $\mathrm{N}$ acetyl-cysteine (NAC) is the standard therapy for APAP overdose (Rumack et al., 1981; Heard, 2008), but there are differences in the route of administration as well as the duration of treatment $(21 \mathrm{~h}$ 


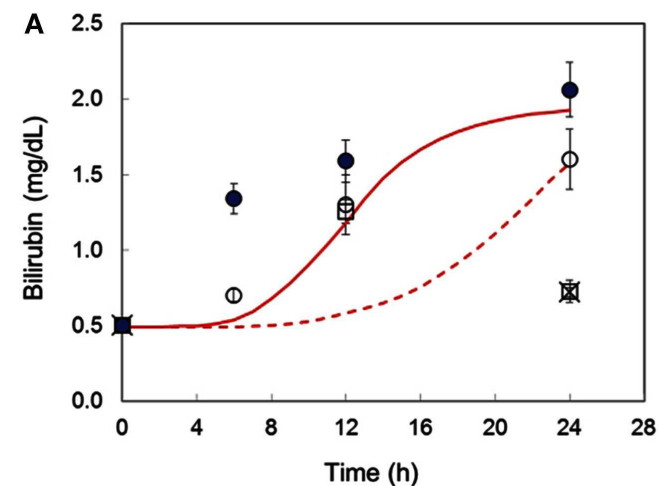

FIGURE 9 | Alternate hypotheses for mechanisms underlying early drug-induced elevation in bilirubin were tested using the DILIsym ${ }^{\mathrm{TM}}$ model. (A) Drug was simulated in the presence (solid line) or absence (dashed line) of an ATP effect on bilirubin formation. Simulation results were compared with published data (Pooranaperundevi et al., 2010a,b), closed and open circles (Nirala and Bhadauria, 2008), x mark (Sawant et al., 2004, open

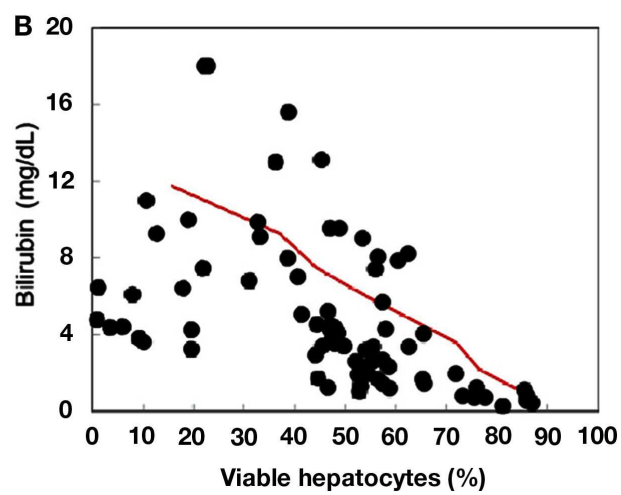

squares), where the presence of an ATP effect on bilirubin formation results in higher fidelity with the published literature for early bilirubin elevation. (B) Drug simulation with the ATP effect on bilirubin formation maintains consistency with the available data describing the relationship between viable hepatocytes and bilirubin (Portmann et al., 1975), circles; simulation results, line). intravenous vs. $72 \mathrm{~h}$ oral) with corresponding debate on the best treatment regime. For example, there are indications that protocol efficacy varies by the length of delay between overdose and treatment initiation (Yarema et al., 2009) and that NAC administration impedes recovery (Athuraliya and Jones, 2009; Yang et al., 2009), providing impetus to identify the shortest effective treatment. Investigative simulations were conducted comparing the standard NAC treatment protocols for $60 \mathrm{~g}$ APAP overdose and varying length of delay between overdose and treatment (4-44 h). The standard $72 \mathrm{~h}$ oral NAC protocol consistently out-performed the $21 \mathrm{~h}$ intravenous (IV) protocol when the delay between overdose and treatment was short; i.e., most pronounced difference in hepatocyte preservation was observed with a $4 \mathrm{~h}$ delay, diminishing to equivalent efficacy with longer delays (Table 1). Mechanistically, the predicted superior efficacy of the oral protocol with short delays can be attributed to the later stage of the treatment cycle, when higher levels of NAC present with the oral protocol more effectively neutralize the remaining APAP and NAPQI (Figure 10A). Prolonging the standard IV protocol such that NAC infusion continued beyond $21 \mathrm{~h}$ improved efficacy (Figure 10B) but did not achieve equivalence with the standard oral protocol in preservation of hepatocytes, due to the overall lower level of NAC administration used in the IV protocol.

Finally, we sought to identify an IV protocol that could provide equivalent efficacy to the standard oral protocol. In 1991, a group of investigators proposed a novel IV protocol which mimics the level of dosing used in the oral protocol but is condensed to $48 \mathrm{~h}$ duration (Smilkstein et al., 1991). They demonstrated its clinical efficacy but were unable to simultaneously evaluate it against standard protocols. Using the DILIsym ${ }^{\mathrm{TM}}$ model, sideby-side simulations confirmed that this protocol has equivalent efficacy to the standard $72 \mathrm{~h}$ protocol (Figure 10C). Further, simulations demonstrate that the higher NAC levels better control peak NAPQI levels accounting for the improved hepatocyte preservation (Figure 10D). This example illustrates how the DILIsym ${ }^{\mathrm{TM}}$ model may be used to compare clinical protocols under multiple
Table 1 |The DILlsym ${ }^{\mathrm{TM}}$ model was applied to compare the efficacy of standard $72 \mathrm{~h}$ oral and $21 \mathrm{~h}$ IV NAC therapy following a $60 \mathrm{~g}$ APAP overdose and varying delays (4-44 h) between overdose and treatment initiation in the baseline human patient.

\begin{tabular}{lll}
\hline $\begin{array}{l}\text { Time elapsed between } \\
\text { overdose and } \\
\text { treatment (h) }\end{array}$ & $\begin{array}{l}\text { 72 } \mathbf{h} \text { oral NAC } \\
\text { (fraction of viable } \\
\text { hepatocytes) }\end{array}$ & $\begin{array}{l}\mathbf{2 1} \mathbf{h} \text { IV NAC } \\
\text { (fraction of viable } \\
\text { hepatocytes) }\end{array}$ \\
\hline 4 & 0.702 & 0.626 \\
9 & 0.615 & 0.546 \\
14 & 0.545 & 0.484 \\
19 & 0.487 & 0.440 \\
24 & 0.437 & 0.413 \\
29 & 0.387 & 0.372 \\
34 & 0.315 & 0.307 \\
39 & $N A$ & $N A$ \\
44 & $N A$ & $N A$ \\
\hline
\end{tabular}

The lowest fraction of viable hepatocytes observed in the experiment was compared. NA indicates APAP overdose resulted in death of the simulated patient despite late NAC treatment (adapted from Woodhead et al., 2012).

scenarios (i.e., length of delay, treatment duration), understand the molecular basis of the predicted efficacy, and identify protocols that improve clinical results. Simulation results could be used to help design confirmatory clinical studies.

The DILIsym ${ }^{\mathrm{TM}}$ model was designed to support decision making throughout the drug lifecycle, including IVIVE, in which in vivo outcomes are predicted using in vitro data. As proof-of-concept, MP was selected for evaluation. Similar to APAP, MP hepatotoxicity is thought to be mediated by a reactive metabolite, but importantly, MP differs from APAP in the observed necrotic pattern (i.e., periportal rather than centrilobular) and in species-specificity (i.e., MP toxicity in rats but not in humans vs. APAP toxicity in both rodents and humans). The model for MP was constructed using in vitro data, including the $\log \mathrm{P}, \mathrm{pKa}$, metabolic partitioning in rat 

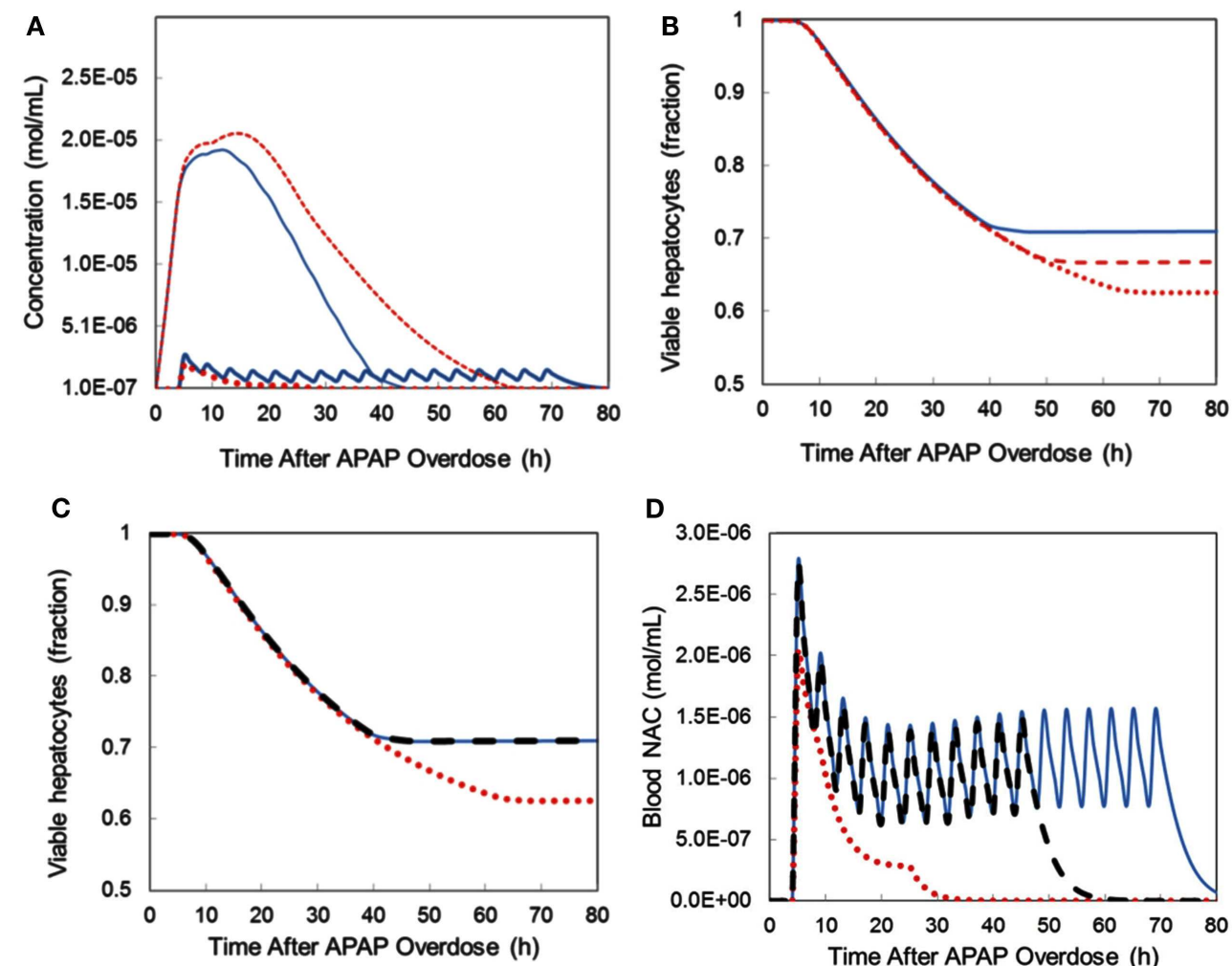

D

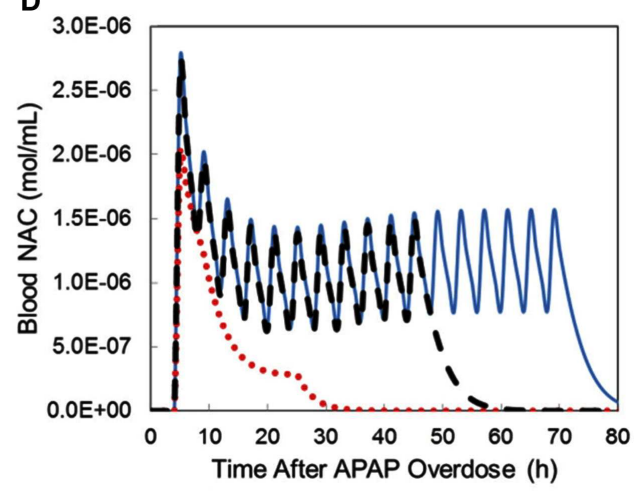

FIGURE 10 |The DILIsym ${ }^{\mathrm{TM}}$ model was applied to evaluate NAC treatment protocols following $\mathbf{6 0} \mathrm{g}$ APAP overdose. (A) NAC was initiated $4 \mathrm{~h}$ after overdose. The level of circulating NAC was compared between standard oral (thick line) and IV (dotted line) NAC protocols and compared against levels of liver NAPQI for oral (thin line) and IV (dashed line) protocols. (B) Hepatocyte viability was compared following application of the standard oral (thick line)

and IV (dotted line) NAC protocols and with extension of the IV NAC protocol to $72 \mathrm{~h}$ (dashed line). (C) Hepatocyte viability was compared following application of the standard oral (thick line) and IV (dotted line) NAC protocols or the Smilkstein IV protocol (Smilkstein et al., 1991; dashed line). (D) Higher NAC levels with the Smilkstein IV protocol (dashed line) better control peak NAPQI levels than standard oral (thick line) or IV (dotted line) protocols.
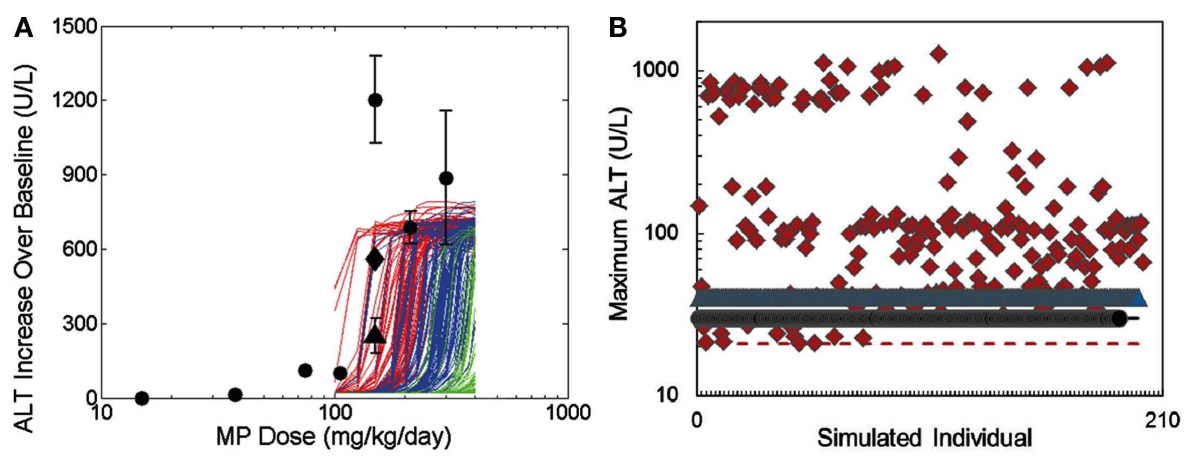

FIGURE 11 |The DILIsym ${ }^{\mathrm{TM}}$ model was evaluated for its ability to predict in vivo liver toxicity given only in vitro input data for the drug methapyrilene. (A) Simulations predict a hepatotoxic threshold of 150-200 mg/kg in rats, consistent with published data (Graichen et al., 1985), circles (Ratra et al., 1998), diamonds (Ratra et al., 2000), triangles. (B) Biological variability represented in alternate simulated individuals yields considerable variability in the strength of liver enzyme signal in rats (diamonds), but persistently, no hepatotoxic signal in humans (circles) or mice (triangles).

and mouse hepatocytes, and covalent binding in mouse, rat, and human microsomes. Multiple doses of MP were evaluated in simulated mice, rats, and humans. The DILIsym ${ }^{\mathrm{TM}}$ model predicted hepatotoxicity in rats between 150 and $200 \mathrm{mg} / \mathrm{kg}$, consistent with the available literature (Figure 11A). MP hepatotoxicity has not been reported in mice; however, it was marketed in the 1950s through the 1970s with no reports of hepatotoxicity, suggesting a safe community experience. With inclusion of variability in the 
underlying biology, all simulated mice and humans were predicted to be tolerant to the drug (Figure 11B), while simulated rats displayed a wide range of response. This example illustrates the IVIVE capability of the DILIsym ${ }^{\mathrm{TM}}$ model.

The DILIsym ${ }^{\mathrm{TM}}$ model is a multi-species, multi-scale mechanistic model for reactive metabolite mediated DILI. The model is based upon APAP datasets, and its capabilities are illustrated above by its application to both APAP research questions (e.g., optimal NAC treatment) and related drugs (e.g., $\mathrm{MP}$ ). Further model development is ongoing and focuses on expanding model capabilities to address other mechanisms of hepatotoxicity.

\section{CONCLUSION}

We have presented some concepts relevant to implementation of a new vision for toxicity testing in the twenty-first century for chemical and pharmaceutical molecules (NAS/NRC, 2007), centered around the idea of critical perturbation to intracellular toxicity pathways and computational systems biology models to

\section{REFERENCES}

Albert, R., and Othmer, H. G. (2003). The topology of the regulatory interactions predicts the expression pattern of the segment polarity genes in Drosophila melanogaster. J. Theor. Biol. 223, 1-18.

Aldridge, B. B., Burke, J. M., Lauffenburger, D. A., and Sorger, P. K. (2006). Physicochemical modelling of cell signalling pathways. Nat. Cell Biol. 8, 1195-1203.

Alon, U. (2007). Network motifs: theory and experimental approaches. Nat. Rev. Genet. 8, 450-461.

An, G. (2001). Agent-based computer simulation and SIRS: building a bridge between basic science and clinical trials. Shock 16, 266-273.

An, G. (2008). Introduction of an agentbased multi-scale modular architecture for dynamic knowledge representation of acute inflammation. Theor. Biol. Med. Model. 5, 11.

An, G., Mi, Q., Dutta-Moscato, J., and Vodovotz, Y. (2009). Agentbased models in translational systems biology. Wiley Interdiscip. Rev. Syst. Biol. Med. 1, 159-171.

Andersen, M. E., Mills, J. J., Jirtle, R. L., and Greenlee, W. F. (1995). Negative selection in hepatic tumor promotion in relation to cancer risk assessment. Toxicology 102, 223-237.

Andrysík, Z., Vondrácek, J., Machala, M., Krcmár, P., Švihálková-Šindlerová, L., Kranz, A., et al. (2007). The aryl hydrocarbon receptor-dependent deregulation of cell cycle control induced by polycyclic aromatic hydrocarbons in rat liver epithelial cells. Mutat. Res. 615, 87-97.

Araujo, R. P., Liotta, L. A., and Petricoin, E. F. (2007). Proteins, drug targets and the mechanisms they control: the simple truth about complex networks. Nat. Rev. Drug Discov. 6, 871-880.

Athuraliya, T. N., and Jones, A. L. (2009). Prolonged N-acetylcysteine therapy in late acetaminophen poisoning associated with acute liver failure - a need to be more cautious? Crit. Care, 13, 144.

Bailey, A. M., Lawrence, M. B., Shang, H., Katz, A. J., and Peirce, S. M. (2009). Agent-based model of therapeutic adipose-derived stromal cell trafficking during ischemia predicts ability to roll on P-selectin. PLoS Comput. Biol. 5:e1000294. doi:10.1371/journal.pcbi.1000294

Bhalla, U. S., and Iyengar, R. (1999). Emergent properties of networks of biological signaling pathways. Science $283,381-387$.

Bhalla, U. S., Ram, P. T., and Iyengar, R. (2002). MAP kinase phosphatase as a locus of flexibility in a mitogenactivated protein kinase signaling network. Science 297, 1018-1023.

Bhattacharya, S., Conolly, R. B., Kaminski, N. E., Thomas, R. S., Andersen, M. E., and Zhang, Q. (2010). A bistable switch underlying B-cell differentiation and its disruption by the environmental contaminant 2,3,7,8tetrachlorodibenzo-p-dioxin. Toxicol. Sci. 115, 51-65.

Bieda, M., Xu, X., Singer, M. A., Green, R., and Farnham, P. J. (2006). Unbiased location analysis of E2F1binding sites suggests a widespread role for E2F1 in the human genome. Genome Res. 16, 595-605.

Bock, K. W., and Kohle, C. (2005). $\mathrm{Ah}$ receptor- and TCDD-mediated liver tumor promotion: clonal selection and expansion of cells evading growth arrest and apoptosis - Commentary. Biochem. Pharmacol. 69, 1403-1408.

understand the topology and dynamic behavior of these pathways. Three case studies were discussed highlighting our ongoing work toward realization of the goals laid out in this vision: (i) causal network mapping of the PPAR $\alpha$ NR pathway in primary human hepatocytes; (ii) a multi-scale agent-based model of the human liver lobule to investigate activation of the AhR pathway in liver parenchymal cells; and (iii) a predictive multi-scale physiological model (DILIsym ${ }^{\mathrm{TM}}$ ) to understand DILI arising from administration of acetaminophen and other drugs. These various approaches will be critical in devising in vitro toxicology testing strategies and determination of pathway targets, as well as improved estimation of dose-response characteristics from a network biology perspective.

\section{ACKNOWLEDGMENTS}

The authors would like to acknowledge support for this work from the American Chemistry Council, the US EPA STAR (Science to Achieve Results) Program (EPA Grant Number: R835000), and the members of the DILI-sim Initiative (www.dilisym.com).

Bogle, G., and Dunbar, P. R. (2010). Agent-based simulation of T-cell activation and proliferation within a lymph node. Immunol. Cell Biol. 88, 172-179.

Bonabeau, E. (2002). Agent-based modeling: methods and techniques for simulating human systems. Proc. Natl. Acad. Sci. U.S.A. 99, 7280-7287.

Borst, P., de Wolf, C., van de Wetering, K. (2007). Multidrug resistanceassociated proteins 3, 4, and 5 . Pflugers Arch. 453, 661-673.

Bourdeau, V., Deschenes, J., Metivier, R., Nagai, Y., Nguyen, D., Bretschneider, N., et al. (2004). Genome-wide identification of high-affinity estrogen response elements in human and mouse. Mol. Endocrinol. 18, 1411-1427.

Boyer, L. A., Lee, T. I., Cole, M. F., Johnstone, S. E., Levine, S. S., Zucker, J. R., et al. (2005). Core transcriptional regulatory circuitry in human embryonic stem cells. Cell 122, 947-956.

Busser, M. T., and Lutz, W. K. (1987). Stimulation of DNA synthesis in rat and mouse liver by various tumor promoters. Carcinogenesis 8 , 1433-1437.

Carlberg, C., and Seuter, S. (2010). Dynamics of nuclear receptor target gene regulation. Chromosoma 119, 479-484.

Carrier, G., Brunet, R. C., and Brodeur, J. (1995). Modeling of the toxicokinetics of polychlorinated dibenzo-pdioxins and dibenzofurans in mammalians, including humans. Toxicol. Appl. Pharmacol. 131, 253-266.

Carroll, J. S., Liu, X. S., Brodsky, A. S., Li, W., Meyer, C. A., Szary, A. J., et al. (2005). Chromosome-wide mapping of estrogen receptor binding reveals long-range regulation requiring the forkhead protein FoxA1. Cell 122, 33-43.

Carroll, J. S., Meyer, C. A., Song, J., Li, W., Geistlinger, T. R., Eeckhoute, J., et al. (2006). Genome-wide analysis of estrogen receptor binding sites. Nat. Genet. 38, 1289-1297.

Chanda, S., Mangipudy, R. S., Warbritton, A., Bucci, T. J., and Mehendale, H. M. (1995). Stimulated hepatic tissue repair underlies heteroprotection by thioacetamide against acetaminophen-induced lethality. Hepatology 21, 477-486.

Chen, Y. H., Lin, F. Y., Liu, P. L., Huang, Y. T., Chiu, J. H., Chang, Y. C., et al. (2009). Antioxidative and hepatoprotective effects of magnolol on acetaminophen-induced liver damage in rats. Arch. Pharm. Res. 32, 221-228.

Chramostová, K., Vondrácek, J., Šindlerová, L., Vojtešek, B., Kozubík, A., and Machala, M. (2004). Polycyclic aromatic hydrocarbons modulate cell proliferation in rat hepatic epithelial stem-like WBF344 cells. Toxicol. Appl. Pharmacol. 196, 136-148.

Danna, E. A., and Nolan, G. P. (2006). Transcending the biomarker mindset: deciphering disease mechanisms at the single cell level. Curr. Opin. Chem. Biol. 10, 20-27.

Davila, A. A., and An, G. (2010). An agent based model of liver damage, inflammation, and repair: in silico translation of cellular and molecular mechanisms to the clinical phenomena of cirrhosis using Netlogo. J. Surg. Res. 158, 411.

Delacroix, L., Moutier, E., Altobelli, G., Legras, S., Poch, O., Choukrallah, M. A., et al. (2010). Cell-specific interaction of retinoic acid receptors with 
target genes in mouse embryonic fibroblasts and embryonic stem cells. Mol. Cell Biol. 30, 231-244.

Dere, E., Forgacs, A. L., Zacharewski, T. R., and Burgoon, L. D. (2011). Genome-wide computational analysis of dioxin response element location and distribution in the human, mouse, and rat genomes. Chem. Res. Toxicol. 24, 494-504.

Dietrich, C., and Kaina, B. (2010). The aryl hydrocarbon receptor (AhR) in the regulation of cell-cell contact and tumor growth. Carcinogenesis 31, 1319-1328.

Elferink, C. J. (2003). Aryl hydrocarbon receptor-mediated cell cycle control. Prog. Cell Cycle Res. 5, 261-267.

El-Samad, H., and Khammash, M. (2006). Regulated degradation is a mechanism for suppressing stochastic fluctuations in gene regulatory networks. Biophys. J. 90, 3749-3761.

Engelberg, J. A., Ropella, G. E. P., and Hunt, C. A. (2008). Essential operating principles for tumor spheroid growth. BMC Syst. Biol. 2:110. doi:10.1186/1752-0509-2-110

Evans, B. R., Karchner, S. I., Allan, L. L., Pollenz, R. S., Tanguay, R. L., Jenny, M. J., et al. (2008). Repression of aryl hydrocarbon receptor (AHR) signaling by AHR repressor: role of DNA binding and competition for AHR nuclear translocator. Mol. Pharmacol. 73, 387-398.

Fausto, N., and Campbell, J. S. (2003). The role of hepatocytes and oval cells in liver regeneration and repopulation. Mech. Dev. 120, 117-130.

Fausto, N., Campbell, J.S., and Riehle, K. J. (2006). Liver regeneration. Hepatology 43, S45-S53.

Ferrell, J. E. Jr. (2002). Self-perpetuating states in signal transduction: positive feedback, double-negative feedback and bistability. Curr. Opin. Cell Biol. 14, 140-148.

Fisher, J. M., Jones, K. W., and Whitlock, J. P. Jr. (1989). Activation of transcription as a general mechanism of 2,3,7,8-tetrachlorodibenzop-dioxin action. Mol. Carcinog. 1, 216-221.

Forger, D. B., and Peskin, C. S. (2003). A detailed predictive model of the mammalian circadian clock. Proc. Natl. Acad. Sci. U.S.A. 100, 14806-14811.

Fullwood, M. J., Liu, M. H., Pan, Y. F., Liu, J., Xu, H., Mohamed, Y. B., et al. (2009). An oestrogen-receptor$\alpha$-bound human chromatin interactome. Nature 462, 58-64.
Gao, H., Fält, S., Sandelin, A., Gustafsson, J. Å., Dahlman-Wright, K. (2008). Genome-wide identification of estrogen receptor $\alpha$-binding sites in mouse liver. Mol. Endocrinol. 22, 10-22.

Gaudio, E., Carpino, G., Cardinale, V., Franchitto, A., Onori, P., and Alvaro, D. (2009). New insights into liver stem cells. Dig. Liver Dis. 41, 455-462.

George, C. L., Lightman, S. L., and Biddie, S. C. (2011). Transcription factor interactions in genomic nuclear receptor function. Epigenomics 3, 471-485.

Gerlee, P., and Anderson, A. R. A. (2009). Evolution of cell motility in an individual-based model of tumour growth. J. Theor. Biol. 259, 67-83.

Gibson, M. A., and Bruck, J. (2000). Efficient exact stochastic simulation of chemical systems with many species and many channels. J. Phys. Chem. A 104, 1876-1889.

Gillespie, D. T. (1976). A general method for numerically simulating the stochastic time evolution of coupled chemical reactions. J. Comput. Phys. 22, 403-434.

Gillespie, D. T. (1977). Exact stochastic simulation of coupled chemical-reactions. J. Phys. Chem. 81, 2340-2361.

Gillespie, D. T. (2000). The chemical Langevin equation. J. Chem. Phys. 113, 297-306.

Gim, J., Kim, H. S., Kim, J., Choi, M., Kim, J. R., Chung, Y. J., et al. (2010). A system-level investigation into the cellular toxic response mechanism mediated by AhR signal transduction pathway. Bioinformatics 26, 2169-2175.

Graichen, M. E., Neptun, D. A., Dent, J. G., Popp, J. A., Leonard, T. B. (1985). Effects of methapyrilene on rat hepatic xenobiotic metabolizing enzymes and liver morphology. Fundam. Appl. Toxicol. 5, 165-174.

Grimm, V., Revilla, E., Berger, U., Jeltsch, F., Mooij, W. M., Railsback, S. F., et al. (2005). Pattern-oriented modeling of agent-based complex systems: lessons from ecology. Science 310, 987-991.

Gueguen, Y., Grandcolas, L., Baudelin, C., Grison, S., Tissandie, E., Jourdain, J. R., et al. (2007). Effect of acetaminophen administration to rats chronically exposed to depleted uranium. Toxicology 229, 62-72.

Heard, K. J. (2008). Acetylcysteine for acetaminophen poisoning. N. Engl. J. Med. 359, 285-292.
Heldring, N., Pike, A., Andersson, S., Matthews, J., Cheng, G., Hartman, J., et al. (2007). Estrogen receptors: how do they signal and what are their targets. Physiol Rev. 87, 905-931.

Howell, B. A., Yang, Y., Kumar, R., Woodhead, J. L., Harrill, A. H., Clewell, H. J. III, et al. (2012). In vitro to in vivo extrapolation and species response comparisons for drug-induced liver injury (DILI) using DILIsym ${ }^{\mathrm{TM}}$, a mechanistic, mathematical model of DILI. J. Pharmacokinet. Pharmacodyn. 39, 527-541.

Hu, S., Yao, G., Guan, X., Ni, Z., Ma, W. Wilson, E. M., et al. (2010). Research resource: genome-wide mapping of in vivo androgen receptor binding sites in mouse epididymis. Mol. Endocrinol. 24, 2392-2405.

Hunt, C. A., Ropella, G. E. P., Yan, L., Hung, D. Y., and Roberts, M. S. (2006). Physiologically based synthetic models of hepatic disposition. J. Pharmacokinet. Pharmacodyn. 33, 737-772.

Jack, J., Wambaugh, J. F., and Shah, I. (2011). Simulating quantitative cellular responses using asynchronous threshold Boolean network ensembles. BMC Syst. Biol. 5:109. doi:10.1186/1752-0509-5-109

Jenner, A. M., and Timbrell, J. A. (1994). Influence of inducers and inhibitors of cytochrome $\mathrm{P} 450$ on the hepatotoxicity of hydrazine in vivo. Arch. Toxicol. 68, 349-357.

John, S., Sabo, P. J., Johnson, T. A. Sung, M. H., Biddie, S. C., Lightman, S. L., et al. (2008). Interaction of the glucocorticoid receptor with the chromatin landscape. Mol. Cell 29, 611-624.

Jones, P. B. C., Galeazzi, D. R., Fisher, J. M., and Whitlock, J. P. Jr. (1985). Control of cytochrome P1-450 gene expression by dioxin. Science 227 1499-1502.

Kaern, M., Elston, T. C., Blake, W. J. and Collins, J. J. (2005). Stochasticity in gene expression: from theories to phenotypes. Nat. Rev. Genet. 6 , 451-464.

Kersten, S., Rakhshandehroo, M. Knoch, B., and Müller, M. (2010). Peroxisome proliferator-activated receptor alpha target genes. PPAR Res. 2010, 612089.

Kholodenko, B. N. (2006). Cellsignalling dynamics in time and space. Nat. Rev. Mol. Cell Biol. 7 , 165-176.

Kholodenko, B. N., Hancock, J. F., and Kolch, W. (2010). Signalling ballet in space and time. Nat. Rev. Mol. Cell Biol. 11, 414-426.
Kim, H., Park, C., Han, K.-H., Choi, J., Kim, Y. B., Kim, J. K., et al. (2004) Primary liver carcinoma of intermediate (hepatocyte-cholangiocyte) phenotype. J. Hepatol. 40, 298-304.

Kuepfer, L. (2010). Towards whole-body systems physiology. Mol. Syst. Biol.6, 409.

Kultz, D. (2005). Molecular and evolutionary basis of the cellular stress response. Annu. Rev. Physiol. 67, 225-257.

Lee, K.-P., Lee, J.-H., Kim, T.-S., Kim, T.-H., Park, H.-D., Byun, J.-S., et al. (2010). The hippo-salvador pathway restrains hepatic oval cell proliferation, liver size, and liver tumorigenesis. Proc. Natl. Acad. Sci. U.S.A. 107, 8248-8253.

Lee, T. I., Rinaldi, N. J., Robert, F., Odom, D. T., Bar-Joseph, Z., Gerber, G. K., et al. (2002). Transcriptional regulatory networks in Saccharomyces cerevisiae. Science 298, 799-804.

Lefebvre, P., Chinetti, G., Fruchart, J. C., and Staels, B. (2006). Sorting out the roles of PPAR $\alpha$ in energy metabolism and vascular homeostasis. $J$. Clin. Invest. 116, 571-580.

Lefterova, M. I., Zhang, Y., Steger, D. J., Schupp, M., Schug, J., Cristancho, A., et al. (2008). PPAR $\gamma$ and C/EBP factors orchestrate adipocyte biology via adjacent binding on a genome-wide scale. Genes Dev. 22, 2941-2952.

Lemire, J. M., Shiojiri, N., and Fausto, N. (1991). Oval cell-proliferation and the origin of small hepatocytes in liver-injury induced by $\mathrm{D}$ galactosamine. Am. J. Pathol. 139, 535-552.

Leung, H. W., Ku, R. H., Paustenbach, D. J., and Andersen, M. E. (1988). A physiologically based pharmacokinetic model for 2,3,7,8tetrachlorodibenzo-p-dioxin in C57BL/6J and DBA/2J mice. Toxicol. Lett. 42, 15-28.

Leung, H. W., Paustenbach, D. J., Murray, F. J., and Andersen, M. E. (1990). A physiological pharmacokinetic description of the tissue distribution and enzymeinducing properties of 2,3,7,8tetrachlorodibenzo-p-dioxin in the rat. Toxicol. Appl. Pharmacol. 103, 399-410.

Libbrecht, L., De Vos, R., Cassiman, D., Desmet, V., Aerts, R., and Roskams, T. (2001). Hepatic progenitor cells in hepatocellular adenomas. Am. J. Surg. Pathol. 25, 1388-1396.

Libbrecht, L., Desmet, V., Van Damme, B., and Roskams, T. (2000). Deep 
intralobular extension of human hepatic 'progenitor cells' correlates with parenchymal inflammation in chronic viral hepatitis: can 'progenitor cells' migrate? J. Pathol. 192, 373-378.

Lindros, K. O., Oinonen, T., Johansson, I., and Ingelman-Sundberg, M. (1997). Selective centrilobular expression of the aryl hydrocarbon receptor in rat liver. J. Pharmacol. Exp. Ther. 280, 506-511.

Losick, R., and Desplan, C. (2008). Stochasticity and cell fate. Science 320 , 65-68.

Mandard, S., Müller, M., and Kersten, S. (2004). Peroxisome proliferatoractivated receptor $\alpha$ target genes. Cell. Mol. Life Sci. 61, 393-416.

Mangan, S., Itzkovitz, S., Zaslaver, A., and Alon, U. (2006). The incoherent feed-forward loop accelerates the response-time of the gal system of Escherichia coli. J. Mol. Biol. 356, 1073-1081.

Mangan, S., Zaslaver, A., and Alon, U. (2003). The coherent feedforward loop serves as a sign-sensitive delay element in transcription networks. J. Mol. Biol. 334, 197-204.

Maronpot, R. R., Foley, J. F., Takahashi, K., Goldsworthy, T., Clark, G., Tritscher, A., et al. (1993). Dose response for TCDD promotion of hepatocarcinogenesis in rats initiated with DEN: histologic, biochemical, and cell proliferation endpoints. Environ. Health Perspect. 101, 634-642.

Michalik, L., and Wahli, W. (2008). PPARs mediate lipid signaling in inflammation and cancer. PPAR Res. 2008:134059. doi: 10.1155/2008/134059

Mills, J. J., and Andersen, M. E. (1993). Dioxin hepatic carcinogenesis - biologically motivated modeling and risk assessment. Toxicol. Lett. 68, 177-189.

Mimura, J., Ema, M., Sogawa, K., and Fujii-Kuriyama, Y. (1999). Identification of a novel mechanism of regulation of $\mathrm{Ah}$ (dioxin) receptor function. Genes Dev. 13, 20-25.

NAS/NRC. (2007). Toxicity Testing in the 21st Century: A Vision and a Strategy. Washington: NAS Press.

Nebert, D. W., Dalton, T. P., Okey, A. B., and Gonzalez, F. J. (2004). Role of aryl hydrocarbon receptormediated induction of the CYP1 enzymes in environmental toxicity and cancer. J. Biol. Chem. 279, 23847-23850.

Nielsen, R., Pedersen, T. Å., Hagenbeek, D., Moulos, P., Siersbæk, R., Megens,
E., et al. (2008). Genome-wide profiling of PPAR $\gamma:$ RXR and RNA polymerase II occupancy reveals temporal activation of distinct metabolic pathways and changes in RXR dimer composition during adipogenesis. Genes Dev. 22, 2953-2967.

Nirala, S. K., and Bhadauria, M. (2008). Propolis reverses acetaminophen induced acute hepatorenal alterations: a biochemical and histopathological approach. Arch. Pharm. Res. 31, 451-461.

Novak, B., and Tyson, J. J. (2003). Modelling the controls of the eukaryotic cell cycle. Biochem. Soc. Trans. 31, 1526-1529.

NTP. (2006a). NTP toxicology and carcinogenesis studies of a mixture of 2,3,7,8Tetrachlorodibenzo-p-dioxin (TCDD) (CAS No. 1746-01-6), 2,3,4,7,8-Pentachlorodibenzofuran (PeCDF) (CAS No. 57117-31-4), and $3,3^{\prime}, 4,4^{\prime}, 5$-Pentachlorobiphenyl (PCB 126) (CAS No. 57465-28-8) in female Harlan Sprague-Dawley rats (Gavage studies). Natl. Toxicol. Program Tech. Rep. Ser. 1-180, abstr. TR-526.

NTP. (2006b). NTP technical report on the toxicology and carcinogenesis studies of $2,2^{\prime}, 4,4^{\prime}, 5,5^{\prime}$-hexachlorobiphenyl (PCB 153) (CAS No. 35065-27-1) in female Harlan Sprague-Dawley rats (Gavage studies). Natl. Toxicol. Program Tech. Rep. Ser. 4-168, abstr. TR-529.

Odom, D. T., Zizlsperger, H., Gordon, D. B., Bell, G. W., Rinaldi, N. J., Murray, H. L., et al. (2004). Control of pancreas and liver gene expression by HNF transcription factors. Science 303, 1378-1381.

Ostapowicz, G., Fontana, R. J., Schiodt, F. V., Larson, A., Davern, T. J., Han, S. H., et al. (2002). Results of a prospective study of acute liver failure at 17 tertiary care centers in the United States. Ann. Intern. Med. 137, 947-954.

Paulusma, C. C., Kool, M., Bosma, P. J., Scheffer, G. L., ter Borg, F., Scheper, R. J., et al. (1997). A mutation in the human canalicular multispecific organic anion transporter gene causes the DubinJohnson syndrome. Hepatology 25, 1539-1542.

Pearson, H. (2008). Cell biology: the cellular hullabaloo. Nature 453, 150-153.

Pitot, H. C., Goldsworthy, T., Campbell, H. A., and Poland, A. (1980). Quantitative-evaluation of the promotion by $2,3,7,8$ tetrachlorodibenzo-para-dioxin of hepatocarcinogenesis from diethylnitrosamine. Cancer Res. 40 , 3616-3620.

Poland, A., and Knutson, J. C. (1982). 2,3,7,8-Tetrachlorodibenzopara-dioxin and related halogenated aromatic-hydrocarbons - examination of the mechanism of toxicity. Annu. Rev. Pharmacol. Toxicol. 22, 517-554.

Pooranaperundevi, M., Sumiyabanu, M. S., Viswanathan, P., Sundarapandiyan, R., and Anuradha, C. V. (2010a) Insulin resistance induced by a high-fructose diet potentiates thioacetamide hepatotoxicity. Singapore Med. J. 51, 389-398.

Pooranaperundevi, M., Sumiyabanu, M. S., Viswanathan, P., Sundarapandiyan, R., and Anuradha, C. V. (2010b). Insulin resistance induced by high-fructose diet potentiates carbon tetrachloride hepatotoxicity. Toxicol. Ind. Health 26 89-104.

Portmann, B., Talbot, I. C., Day, D. W., Davidson, A. R., Murray-Lyon, I. M., Williams, R. (1975). Histopathological changes in the liver following a paracetamol overdose: correlation with clinical and biochemical parameters. J. Pathol. 117, 169-181.

Proctor, C. J., and Gray, D. A. (2008). Explaining oscillations and variability in the p53-Mdm2 system. BMC Syst. Biol. 2:75. doi:10.1186/17520509-2-75

Pyper, S. R., Viswakarma, N., Yu, S., and Reddy, J. K. (2010). PPARalpha: energy combustion, hypolipidemia, inflammation and cancer. Nucl. Recept. Signal. 8: $\mathrm{e} 002$.

Rathinam, M., Petzold, L. R., Cao, Y., and Gillespie, D. T. (2003). Stiffness in stochastic chemically reacting systems: the implicit tauleaping method. J. Chem. Phys. 119, 12784-12794.

Ratra, G. S., Morgan, W. A., Mullervy, J., Powell, C. J., and Wright, M. C. (1998). Methapyrilene hepatotoxicity is associated with oxidative stress, mitochondrial disfunction and is prevented by the $\mathrm{Ca} 2+$ channel blocker verapamil. Toxicology 130, 79-93.

Ratra, G. S., Powell, C. J., Park, B. K., Maggs, J. L., and Cottrell, S. (2000). Methapyrilene hepatotoxicity is associated with increased hepatic glutathione, the formation of glucuronide conjugates, and enterohepatic recirculation. Chem. Biol. Interact. 129, 279-295.
Ravasi, T., Suzuki, H., Cannistraci, C. V., Katayama, S., Bajic, V. B., Tan, K., et al. (2010). An atlas of combinatorial transcriptional regulation in mouse and man. Cell 140, 744-752.

Reddy, J. K., Azarnoff, D. L., and Hignite, C. E. (1980). Hypolipidemic hepatic peroxisome proliferators form a novel class of chemical carcinogens. Nature 283, 397-398.

Reddy, J. K., Rao, M. S., and Moody, D. E. (1976). Hepatocellular carcinomas in acatalasemic mice treated with Nafenopin, a hypolipidemic peroxisome proliferator. Cancer Res. 36, 1211-1217.

Reddy, T. E., Pauli, F., Sprouse, R. O., Neff, N. F., Newberry, K. M., Garabedian, M. J., et al. (2009). Genomic determination of the glucocorticoid response reveals unexpected mechanisms of gene regulation. Genome Res. 19, 2163-2171.

Robrechts, C., De Vos, R., Van den Heuvel, M., Van Cutsem, E., Van Damme, B., Desmet, V., et al. (1998). Primary liver tumour of intermediate (hepatocyte bile duct cell) phenotype: a progenitor cell tumour? Liver 18, 288-293.

Rosenfeld, N., Elowitz, M. B., and Alon, U. (2002). Negative autoregulation speeds the response times of transcription networks. J. Mol. Biol. 323, 785-793.

Roskams, T. A., Libbrecht, L., and Desmet, V. J. (2003). Progenitor cells in diseased human liver. Semin. Liver Dis. 23, 385-396.

Rothenberg, E. V. (2007). Cell lineage regulators in $\mathrm{B}$ and $\mathrm{T}$ cell development. Nat. Immunol. 8, 441-444.

Rowlands, J. C., and Gustafsson, J. A. (1997). Aryl hydrocarbon receptormediated signal transduction. Crit. Rev. Toxicol. 27, 109-134.

Rowlands, J. C., McEwan, I. J., and Gustafsson, J. Ã. (1996). Transactivation by the human aryl hydrocarbon receptor and aryl hydrocarbon receptor nuclear translocator proteins: direct interactions with basal transcription factors. Mol. Pharmacol. 50, 538-548.

Rumack, B. H., Peterson, R. C., Koch, G. G., and Amara, I. A. (1981) Acetaminophen overdose. 662 cases with evaluation of oral acetylcysteine treatment. Arch. Intern. Med. $141,380-385$.

Salis, H., and Kaznessis, Y. (2005). Accurate hybrid stochastic simulation of a system of coupled chemical or biochemical reactions. J. Chem. Phys. 122,54103 . 
Sawant, S. P., Dnyanmote, A. V., Shankar, K., Limaye, P. B., Latendresse, J. R., and Mehendale, H. M. (2004). Potentiation of carbon tetrachloride hepatotoxicity and lethality in type 2 diabetic rats. J. Pharmacol. Exp. Ther. 308, 694-704.

Schmidt, J. V., and Bradfield, C. A. (1996). Ah receptor signaling pathways. Annu. Rev. Cell Dev. Biol. 12, 55-89.

Sewall, C. H., Bell, D. A., Clark, G. C., Tritscher, A. M., Tully, D. B., Heuvel, J. V., et al. (1995). Induced gene-transcription - implications for biomarkers. Clin. Chem. 41, 1829-1834.

Shah, I., and Wambaugh, J. (2010). Virtual tissues in toxicology. J. Toxicol. Environ. Health B Crit. Rev. 13, 314-328.

Shen-Orr, S. S., Milo, R., Mangan, S., and Alon, U. (2002). Network motifs in the transcriptional regulation network of Escherichia coli. Nat. Genet. 31, 64-68.

Siersbæk, R., Nielsen, R., and Mandrup, S. (2010). PPARgamma in adipzocyte differentiation and metabolism - novel insights from genomewide studies. FEBS Lett. 584, 3242-3249.

Simmons, S. O., Fan, C. Y., and Ramabhadran, R. (2009). Cellular stress response pathway system as a sentinel ensemble in toxicological screening. Toxicol. Sci. 111, 202-225.

Smilkstein, M. J., Bronstein, A. C., Linden, C., Augenstein, W. L., Kulig, K. W., and Rumack, B. H. (1991). Acetaminophen overdose: a 48-hour intravenous $\mathrm{N}$-acetylcysteine treatment protocol. Ann. Emerg. Med. 20, 1058-1063.

So, A. Y., Chaivorapol, C., Bolton, E. C., Li, H., and Yamamoto, K. R. (2007). Determinants of cell- and gene-specific transcriptional regulation by the glucocorticoid receptor. PLoS Genet. 3:e94. doi:10.1371/journal.pgen.0030094

Stender, J. D., Kim, K., Charn, T. H., Komm, B., Chang, K. C. N., Kraus, W. L., et al. (2010). Genome-wide analysis of estrogen receptor $\alpha$ DNA binding and tethering mechanisms identifies Runxl as a novel tethering factor in receptor-mediated transcriptional activation. Mol. Cell Biol. 30, 3943-3955.

Sugimura, Y., and Yamamoto, K. (1998). Effect of orally administered reduced- and oxidized-glutathione against acetaminophen-induced liver injury in rats. J. Nutr. Sci. Vitaminol. 44, 613-624.
Sun, T., McMinn, P., Coakley, S., Holcombe, M., Smallwood, R., and MacNeil, S. (2007). An integrated systems biology approach to understanding the rules of keratinocyte colony formation. J. R. Soc. Interface 4, 1077-1092.

Swameye, I., Muller, T. G., Timmer, J., Sandra, O., and Klingmuller, U. (2003). Identification of nucleocytoplasmic cycling as a remote sensor in cellular signaling by databased modeling. Proc. Natl. Acad. Sci. U.S.A. 100, 1028-1033.

Swiers, G., Patient, R., and Loose M. (2006). Genetic regulatory networks programming hematopoietic stem cells and erythroid lineage specification. Dev. Biol. 294, 525-540.

Tiribelli, C., and Ostrow, J. D. (1996) New concepts in bilirubin and jaundice: report of the Third International Bilirubin Workshop, April 6-8, 1995, Trieste, Italy. Hepatology 24, 1296-1311.

Tritscher, A. M., Clark, G. C., Sewall, C., Sills, R. C., Maronpot, R., and Lucier, G. W. (1995). Persistence of Tcddinduced hepatic cell-proliferation and growth of enzyme-altered foci after chronic exposure followed by cessation of treatment in den initiated female rats. Carcinogenesis 16, 2807-2811.

Tyson, J. J., Chen, K. C., and Novak, B. (2003). Sniffers, buzzers, toggles and blinkers: dynamics of regulatory and signaling pathways in the cell. Curr. Opin. Cell Biol. 15, 221-231.

U.S.EPA. (2009). The U.S. Environmental Protection Agency's Strategic Plan for Evaluating the Toxicity of Chemicals. EPA100/K-09/001. Washington, DC: U.S. Environmental Protection Agency.

van der Meer, D. L. M., Degenhardt, T., Väisänen, S., de Groot, P. J., Heinäniemi, M., de Vries, S. C., et al. (2010). Profiling of promoter occupancy by PPAR $\alpha$ in human hepatoma cells via ChIPchip analysis. Nucleic Acids Res. 38, 2839-2850.

Vanlier, J., Tiemann, C. A., Hilbers, P. A., and van Riel, N. A. (2012). An integrated strategy for prediction uncertainty analysis. Bioinformatics 28, 1130-1135.

Vendemiale, G., Grattagliano, I., Altomare, E., Turturro, N., and Guerrieri, F. (1996). Effect of acetaminophen administration on hepatic glutathione compartmentation and mitochondrial energy metabolism in the rat. Biochem. Pharmacol. 52, 1147-1154.
Viluksela, M., Bager, Y., Tuomisto, J. T., Scheu, G., Unkila, M., Pohjanvirta, R., et al. (2000). Liver tumor-promoting activity of 2,3,7,8-tetrachlorodibenzo-pdioxin (TCDD) in TCDD-sensitive and TCDD-resistant rat strains. Cancer Res. 60, 6911-6920.

Vodovotz, Y. (2006). Deciphering the complexity of acute inflammation using mathematical models. Immunol. Res. 36, 237-245.

Walker, D. C., Hill, G., Wood, S. M. Smallwood, R. H., and Southgate, J. (2004). Agent-based computational modeling of wounded epithelial cell monolayers. IEEE Trans. Nanobioscience 3, 153-163.

Wambaugh, J., and Shah, I. (2010). Simulating microdosimetry in a virtual hepatic lobule. PLoS Comput. Biol. 6:e1000756. doi:10.1371/journal.pcbi.1000756

Wang, P. Y., Kaneko, T., Wang, Y. and Sato, A. (1999). Acarbose alone or in combination with ethanol potentiates the hepatotoxicity of carbon tetrachloride and acetaminophen in rats. Hepatology 29, 161-165.

Waters, E., Wang, J. H., Redmond, H. P., Wu, Q. D., Kay, E., and BouchierHayes, D. (2001). Role of taurine in preventing acetaminophen-induced hepatic injury in the rat. Am. J. Physiol. Gastrointest. Liver Physiol. 280, G1274-G1279.

Weiss, C., Faust, D., Schreck, I., Ruff, A., Farwerck, T., Melenberg, A., et al. (2008). TCDD deregulates contact inhibition in rat liver oval cells via Ah receptor, JunD and cyclin A. Oncogene 27, 2198-2207.

Whysner, J., and Williams, G. M. (1996). 2,3,7,8-Tetrachlorodibenzop-dioxin mechanistic data and risk assessment: gene regulation, cytotoxicity, enhanced cell proliferation, and tumor promotion. Pharmacol. Ther. 71, 193-223.

Woodhead, J. L., Howell, B. A. Yang, Y., Harrill, A. H., Clewell, H. J. III, Andersen, M. E., et al. (2012). An analysis of $\mathrm{N}$ acetylcysteine treatment for acetaminophen overdose using a systems model of drug-induced liver injury. J. Pharmacol. Exp. Ther. 342, 529-540.

Worner, W., and Schrenk, D. (1996). Influence of liver tumor promoters on apoptosis in rat hepatocytes induced by 2 -acetylaminofluorene, ultraviolet light, or transforming growth factor beta 1. Cancer Res. 56, 1272-1278.

Yang, R., Miki, K., He, X., Killeen, M. E. and Fink, M. P. (2009). Prolonged treatment with $\mathrm{N}$-acetylcystine delays liver recovery from acetaminophen hepatotoxicity. Crit. Care 13, R55.

Yarema, M. C., Johnson, D. W., Berlin, R. J., Sivilotti, M. L., Nettel-Aguirre, A., Brant, R. F., et al. (2009). Comparison of the 20-hour intravenous and 72-hour oral acetylcysteine protocols for the treatment of acute acetaminophen poisoning. Ann. Emerg. Med. 54, 606-614.

Zandbergen, F., and Plutzky, J. (2007). $\operatorname{PPAR} \alpha$ in atherosclerosis and inflammation. Biochim. Biophys. Acta 1771, 972-982.

Zeng, Q., and Hong, W. (2008). The emerging role of the hippo pathway in cell contact inhibition, organ size control, and cancer development in mammals. Cancer Cell 13, 188-192.

Zhang, Q., and Andersen, M. E. (2007). Dose response relationship in anti-stress gene regulatory networks. PLoS Comput. Biol. 3:e24. doi:10.1371/journal.pcbi. 0030024

Zhang, Q., Bhattacharya, S., Andersen, M. E., and Conolly, R. B. (2010a). Computational systems biology and dose-response modeling in relation to new directions in toxicity testing. J. Toxicol. Environ. Health B Crit. Rev. 13, 253-276.

Zhang, Q., Bhattacharya, S., Kline, D. E., Crawford, R. B., Conolly, R. B., Thomas, R. S., et al. (2010b). Stochastic modeling of B lymphocyte terminal differentiation and its suppression by dioxin. BMC Syst. Biol. 4:40. doi:10.1186/1752-05094-40

Zhang, W., Chen, X.-P., Zhang, W.G., Zhang, F., Xiang, S., Dong, H.-H., et al. (2009a). Hepatic non-parenchymal cells and extracellular matrix participate in oval cell-mediated liver regeneration. World J. Gastroenterol. 15, 552-560.

Zhang, L., Strouthos, C. G., Wang, Z., and Deisboeck, T. S. (2009b) Simulating brain tumor heterogeneity with a multiscale agent-based model: linking molecular signatures, phenotypes and expansion rate. Math. Comput. Model. 49, 307-319.

Zhang, L., Wang, Z. H., Sagotsky, J. A., and Deisboeck, T. S. (2009c). Multiscale agent-based cancer modeling. J. Math. Biol. 58, 545-559.

Zieve, L., Anderson, W. R., Dozeman, R., Draves, K., and Lyftogt, C. (1985). Acetaminophen liver injury: 
sequential changes in two biochemical indices of regeneration and their relationship to histologic alterations. J. Lab. Clin. Med. 105, 619-624.

Conflict of Interest Statement: The authors declare that the research was conducted in the absence of any commercial or financial relationships that could be construed as a potential conflict of interest.

Received: 25 July 2012; accepted: 21 November 2012; published online: 14 December 2012.

Citation: Bhattacharya S, Shoda LKM, Zhang Q, Woods CG, Howell BA, Siler $S Q$, Woodhead JL, Yang Y, McMullen
P, Watkins $P B$ and Andersen $M E$ (2012) Modeling drug- and chemicalinduced hepatotoxicity with systems biology approaches. Front. Physio. 3:462. doi: 10.3389/fphys.2012.00462

This article was submitted to Frontiers in Systems Biology, a specialty of Frontiers in Physiology.

Copyright $\odot 2012$ Bhattacharya, Shoda, Zhang, Woods, Howell, Siler, Woodhead,
Yang, McMullen, Watkins and Andersen. This is an open-access article distributed under the terms of the Creative Commons Attribution License, which permits use, distribution and reproduction in other forums, provided the original authors and source are credited and subject to any copyright notices concerning any third-party graphics etc. 